\title{
Effects of extreme environmental exposure conditions on the mechanical behaviour of traditional carpentry joints
}

\author{
E. Poletti ${ }^{*}$, G. Vasconcelos, J.M. Branco, B. Isopescu ${ }^{1}$ \\ ISISE, Institute of Science and Innovation for Bio-Sustainability (IB-S), University of Minho, Department of Civil Engineering, Campus de Azurém, 4800-058 Guimarães, Portugal
}

H I G H L I G H T S

- Joints govern the behaviour of a timber structures.

- Weathering of the joint generally caused a degeneration of the joint's performance.

- Weathered joints with steel plates decreased their capacity by $31 \%$.

\section{A R T I C L E I N F O}

Article history:

Received 24 October 2018

Received in revised form 4 March 2019

Accepted 5 April 2019

\section{Keywords:}

Environmental conditions

Timber joints

Weathering

Cyclic tests

Traditional structures

\begin{abstract}
A B S T R A C T
Timber-framed architecture is an important heritage common of many countries. However, this is being lost due to natural decay but also climatic changes and natural hazards. To preserve it, it is important to understand the influence of such actions.

Timber joints significantly affect the mechanical performances of timber-framed buildings, being the weakest element.

In this paper, results are presented from cyclic pull-out test conducted on traditional timber joints subjected to wind driven rain and flood, both unreinforced and retrofitted, and a comparison is made with those obtained from sound specimens. Wetting-drying cycles mainly influence the stiffness and dissipation capacity.
\end{abstract}

(c) 2019 Elsevier Ltd. All rights reserved.

\section{Introduction}

Timber-framed buildings are a common traditional construction system in many countries, both in Europe and across the world: France (Colombage structures), Italy (Baraccata system), England (half-timbered), Germany (fachwerk), Greece (ksilopikti tichopiia), Portugal (Pombalino buildings), Romania (paianta), Scandinavia (bindingsverk), Spain (entramados), Turkey (Hımış), Colombia (bahareque), Haiti (Gingerbread houses), Kashmir (dhajji-dewari), Peru (quincha), USA (balloon frame which evolved to the stud frame) etc. They are typically part of local vernacular architecture styles, and they constitute an important cultural heritage worth preserving. They present characteristics which vary from country to country in terms of architectural and structural typology, geometry and materials [1].

\footnotetext{
* Corresponding author.

E-mail addresses: elisapoletti@civil.uminho.pt (E. Poletti), graca@civil.uminho.pt (G. Vasconcelos), jbranco@civil.uminho.pt (J.M. Branco).

${ }^{1}$ Department of Civil Engineering and Building Services Engineering, Faculty of Civil Engineering, 'Politehnica' University of Timisoara.
}

Traditional timber-framed buildings consist of a timber frame (posts and beams), with or without bracings, with varying crosssections and geometrical disposition, which can be filled with different materials, e.g. mud, brick masonry, rubble stone masonry or covered with bamboo canes, wooden planks, etc. Different types of wood can be used for framing depending on the location (local species were usually adopted). The timber frame elements are connected by means of traditional carpentry joints (e.g. dovetail joints, half-lap, mortise and tenon) and nails.

In Northern European countries timber-framed buildings are common due to the abundance of wood and the easy and cheap construction they offer (Fig. 1). Due to the good seismic resistance they are also frequently used in areas prone to seismic activity (i.e. Southern European countries). There is a great diversity also in scale and "importance", varying from monumental buildings (e.g. churches) to humble buildings (e.g. barns), but all are still an important part of our cultural heritage.

Due to their good seismic performance observed in recent past earthquakes [2], this traditional structural system has been adopted in reconstruction programs after devastating earthquakes all over the world (e.g. the use of quincha mejorada in Peru and the 


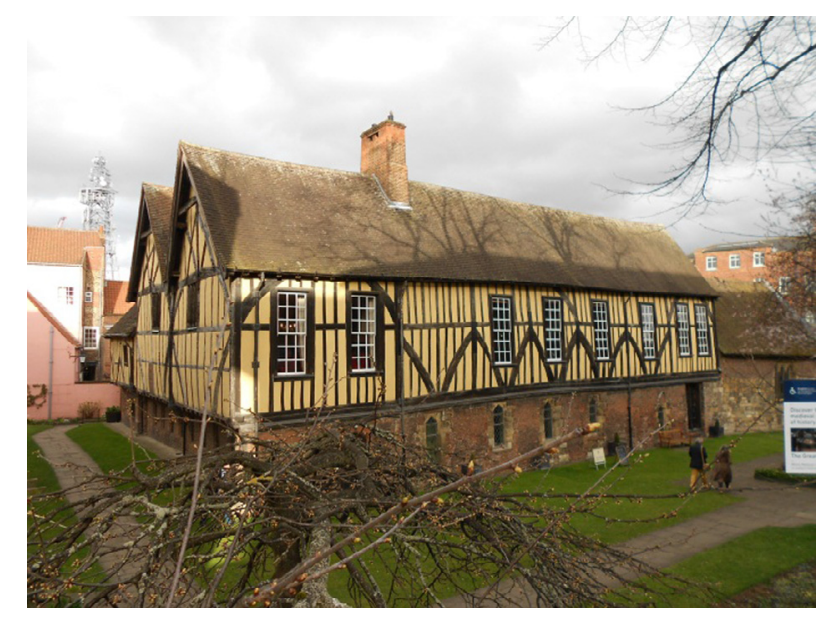

Fig. 1. York's Merchant Adventurers' Hall (UK).

adoption of timber-framed houses and relative training organised after the 2005 Kashmir earthquake to rebuild the area). However, this effort has been recognised only as a temporary solution, without acknowledging its full potential, even though historic data have shown that timber-framed buildings were recommended for seismic areas. It is also considered that this structural system constitutes an environmentally friendly solution, which, in the context of climate change adaptation represents a serious and promising option for sustainable construction through its use of local materials and low embodied energy.

Another point to be taken into consideration is the lack or poor maintenance of these structures. Even for those cases where the external timber-framed walls have a finishing, usually a mortar cover with or without a metal mesh to avoid separation, poor maintenance can lead to the loss of this cover, leading timber elements to have contact with external weather conditions (Fig. 2).

With the climatic changes that have been significantly affecting Europe in the last decades, many of these structures are subjected to extreme actions (floods, storms, heat-cold waves, freeze-thaw cycles, etc.) that were not taken into consideration when built or when interventions were made. For example, considering the extreme changes in temperatures and the fact that many of these structures present shallow foundations on soft soils (particularly in UK, Scandinavia, Germany, France), subsidence may occur leading to great damages to structures. Financial loss from structural damages due to soil subsidence has increased by more than $50 \%$ since the 1970 s, and it is projected to rise significantly more in the changing climate (in this direction, insurance policies have known a considerable increase in the last decades). In addition, Europe in general has been hit by exceptional floods, storms and tornadoes (e.g. Slovenia 2008, Germany 2013, UK 2014, Italy 2015). Such events affect a mixed system such as timber-framed buildings, where the main structural part (the timber frame) and the infill have a different response and an in depth analysis for the risks involved for each component is paramount. It is therefore essential to bring together specialist from different areas to assess the problem and find appropriate solutions.

\subsection{Current studies available}

Few studies address the effect of weathering on timber-framed buildings. Research has been carried out on the risks associated with flood hazards in the UK [3], focusing on historic structures, including timber-framed ones. A new methodology was presented, studying the nature of the vulnerability of these structures to floods by means of appraising vulnerability indicators related to building form, structural and fabric integrity, and preservation of architectural and archaeological values. The authors also carried out an experimental campaign with simulated wind driven rain on reduced scale traditional timber-framed walls with masonry infill, where degradation was observed in both the frame and the infill. At testing (cyclic testing) a great loss of stiffness and a moderate loss of strength were observed for the wet walls.

Bradley et al. [4] studied the effect of simulated flooding on the structural performance of light timber frame shear walls (without infill but with sheathing panels). The walls were then tested in control, wet and restored conditions. There were significant losses in mechanical strength for both the wet $(20 \%)$ and the restored (25\%) walls tested. A study connected to this one took into account the performance of these walls with different drying conditions [5]. Considering different drying conditions, all dried specimens suffered a reduction in connection strength and a loss in connection stiffness. The energy dissipation potential for the dried specimens was consistently less than those in the original condition, but the recovery of the dissipative potential varies with the rate of drying.

Pazlar and Kramar [6] presented a discussion on the extreme weather conditions impact on traditional timber structures. Their main conclusions pointed out the need for preventive maintenance

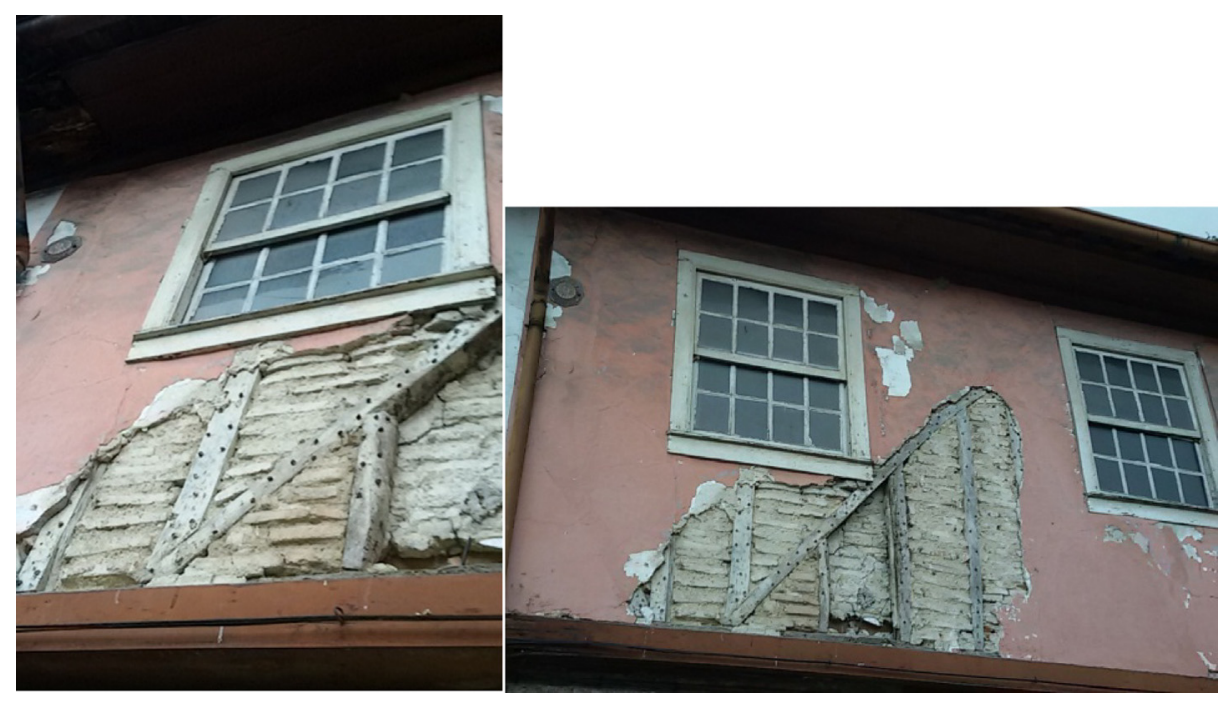

Fig. 2. Loss of covering in traditional timber-framed house in Guimarães, Portugal. 
of vernacular architecture to prevent infiltrations and possibilities of local collapses and the need to implement a cultural heritage disaster risk management.

\subsection{Climate change and its influence on timber structures}

Climate change is defined by the United Nations Framework Convention on Climate Change (UNFCCC) (UN, 1992), in its Article 1 , as a change of climate directly or indirectly attributed to human activity that alters the composition of the global atmosphere and the natural climate variability observed over comparable time periods.

The Intergovernmental Panel on Climate Change (IPCC) states in its Third Assessment Report (2001) that 'The Earth's climate system has demonstrably changed on both global and regional scales since the preindustrial era, with some of these changes attributed to human activities'. To limit the extent of climate change, the reduction of the emission and enhancing the sinks of greenhouse gases is needed, but the same report mentions that 'adaptation is a necessary strategy at all scales to complement climate change mitigation efforts [7].

Climate change will have physical, social and cultural impacts on cultural heritage. It will change the way people relate to their environment. This relationship is characterised by the way people live, work, worship and socialize in buildings, sites and landscapes with heritage values. The character of cultural heritage, namely built heritage, is closely related to the climate. Climate change can be subtle occurring over a long period of time. However, some climate change parameters such as freezing, temperature and relative humidity shock can change by large amounts over a short period of time.

Regarding World Heritage properties, the most common threats of climate change reported are induced by rainfall (storms, floods and wind driven rain) and they make up for approximately $22 \%$ of all threats.

According to recent climatic risk maps (Fig. 3) [8], the majority of extreme climatic conditions will increase in intensity and in duration. The weathering effects to which historic and vernacular structures are exposed to will be more intense and thus more damaging. The prediction results consist in a decrease in annual precipitation in Southern Europe and an increase in Northern Europe.
All areas of Europe will experience rainy periods longer than five days in both the near and the far future. Long rainy periods can cause accelerated deterioration of organic as well as inorganic materials due to changes in volume, an increased risk of biological attack as well as possible frost damage. Moreover, the amount of precipitation can trigger natural disasters like floods and landslides, as the reduction of rainy periods can cause draught and wild fire [8].

Water acts on historic materials and structures in all its phases and together with temperature or other parameters, can cause decay or even destroy a monument if protective measures are not taken. The interaction of temperature and moisture causes repeated and uneven volumetric changes resulting in the propagation of defects.

Floods cause damage and failure due to static and dynamic loads (water pressure, water flow, uplift forces), due to the impact of floating objects, due to the wetting of building materials (which are difficult to dry) and due to the risk of transfer of chemical pollutants and biological contamination.

The dual action of temperature and moisture alteration is of particular danger to timber, since it can cause early decay, propagation of cracks and even failure. Wooden architecture is mainly spread in the Northern, Central and Eastern part of Europe, where climatic changes are expected to shift to more extensive wet periods.

\subsection{Experimental research on traditional timber-framed structures and joints}

Many rehabilitation works are being conducted on traditional half-timbered structures, most of them adopting text book retrofitting solutions, without investing the research time necessary to develop a specific solution for each situation encountered. Most of these interventions do not provide an efficient strengthening solution (ranging from aesthetics, the extent of the intervention to the new mechanical properties achieved).

Few experimental works have been carried out until now to assess the seismic behaviour of timber-framed walls. Reports have been written after recent earthquakes to quantify the qualitative performance of half-timbered structures [9-12], showcasing their optimal response to seismic actions and how they were able to withstand less damage compared to modern reinforced concrete (RC) buildings.
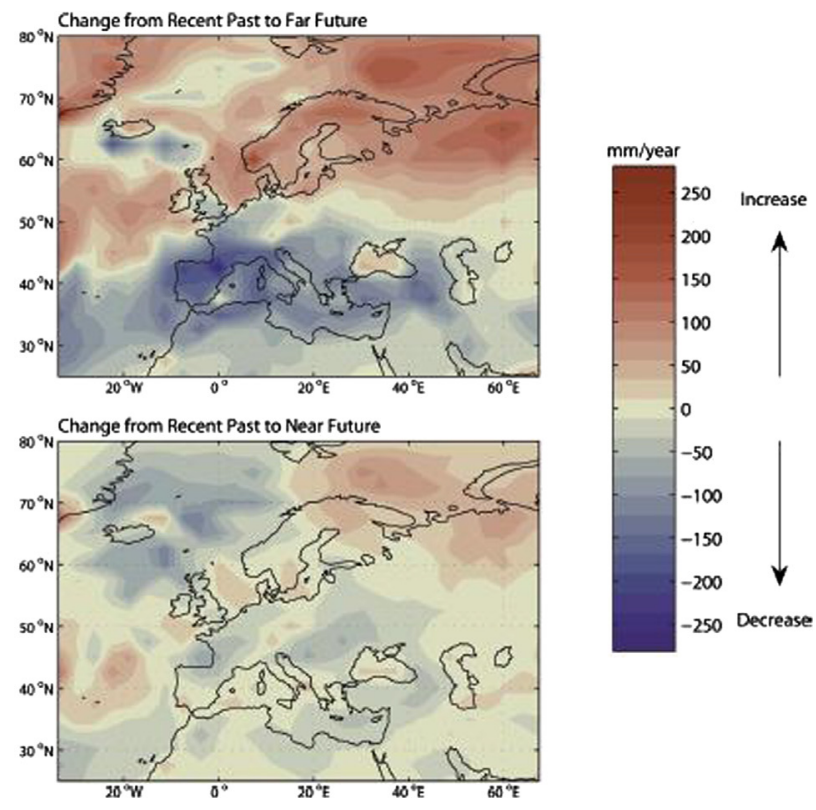
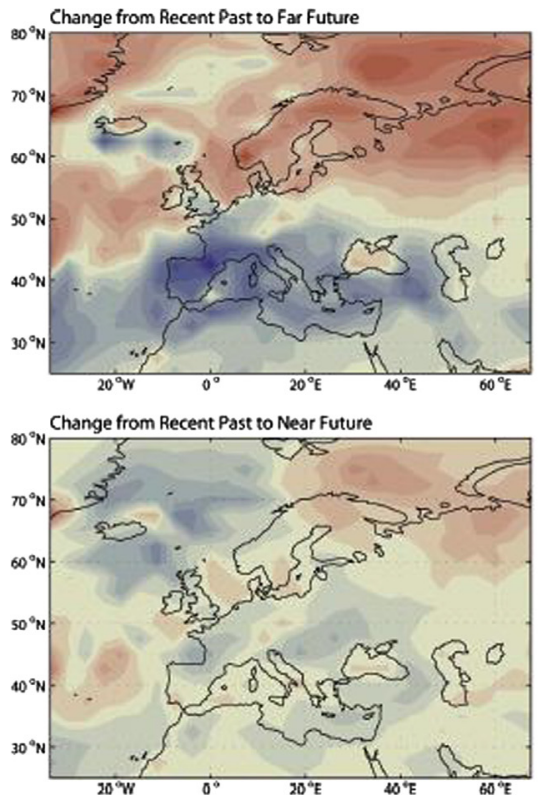

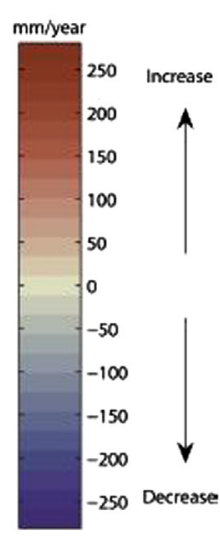

Fig. 3. Annual (left) and consecutive (>5 days) (right) precipitation increase [8]. 
In recent years, studies assessing the experimental behaviour of traditional half-timbered walls and their retrofitting solutions have been carried out [13-16], pointing out the excellent behaviour of timber-framed walls as shear walls. Work on retrofitting traditional Pombalino building from Lisbon have been done by using FRP sheets for the connection strengthening [17], by including damping systems consisting of injected anchors and bracing systems linked to frontal walls and to the outer masonry [17]. Other types of timber-framed walls have been studied experimentally with geometries from all over the world, e.g. Italy [18], Peru [19], Haiti [20], Romania [21]. However, little to no work has been carried out on environmental conditions now affecting seismic regions.

The experimental work regarding timber connections tend to be concentrated around universities or research institutions mainly investigating local typologies and cases. Various studies are found in the literature assessing the mechanical behaviour of traditional joints, namely of birdsmouth connections [22,23], rounded dovetail connections [24], mortise and tenon [25-27], dowel-type connections [28], wood pegged timber frames [29], traditional Nuki joints [30], Dou-Gon joints [31], steel-wood nail connections [32], among many others. A vast number of studies on retrofitting techniques for traditional timber connections are also available, namely birdsmouth joint reinforcements [22,23], and glass fibre reinforced polymers (GFRP) reinforcement [33].

It is considered that taking into account the possible effects of extreme wet and dry conditions associated to climatic changes in timber-framed buildings, it is increasingly relevant to know in a detailed and clear way their effects on their mechanical behaviour and on some components since this information is missing. Therefore, it was decided to design an experimental campaign to evaluate the influence of cyclic wet and dry cycles on the mechanical behaviour of timber connections typical of timber-framed walls. Two phases were considered: (1) definition of an experimental campaign aiming to simulate the wet and dry cycles on the connections; (2) mechanical characterization of the unreinforced and reinforced timber connection to pull-out loads.

\section{Wetting/drying cycles for accelerated weathering}

As previously mentioned, following the increasing relevance of climate induced damage to the envelope of traditional buildings and the durability changes of the constituting materials, it was decided to carry out an exploratory work aiming to analyse the effect of different extreme environmental conditions regarding the mechanical behaviour of traditional timber connections.

In particular, traditional timber joints were subjected to wetting/drying cycles for different time periods as well as to the simulation of a flood event with a subsequent drying period. Afterwards, the joints were tested mechanically, comparing the results to those of sound joints [34].

\subsection{Brief description of timber joints specimens}

The joint selected to perform these tests was the half-lap joint, a carpentry joint often encountered in timber-framed structures. This joint had already been tested in non-weathered conditions [34] and results are available in order to compare the effect of weathering on the joint. The joints had the same geometry and the same wood specie, Pinus pinaster.

Three types of specimens were considered: unreinforced specimens (Fig. 4), specimens strengthened with self-tapping screws (Fig. 5) and specimens strengthened with steel plates (Fig. 6). The strengthening was performed in a similar way to that done for the sound specimens [34] in order to allow to compare results.

Strengthening done with self-tapping screws was performed according to the configuration presented in Fig. 5. The screws (VGZ9200 by Rothoblaas) had an inclination of $60^{\circ}$ and $45^{\circ}$ and were placed two on each side of the joint. This type of strengthening requires the removal of the infill and is reversible.

Lastly, strengthening performed with steel plates (PF703085 $(140 \times 400 \mathrm{~mm})$ made of steel S $250 \mathrm{GD}$ and having a thickness of $2 \mathrm{~mm}$ secured with PF603550 screws from Rothoblaas and $ø 10 \mathrm{~mm}$ bolts) is shown in Fig. 6.

Additionally, for all specimens the gripping area was strengthened with GFRP sheets in order to avoid failure in the gripping zone (Fig. 7a). This was done in the same plane where the strengthening was applied. Moreover, plastic sheets were glued laterally to the joint to simulate the presence of infill with $1 \mathrm{~cm}$ of margin (Fig. 7b). In this way, the water could not reach the back of the joint, simulating real conditions.

Due to limited resources and time, 6 specimens were considered for wind driven rain (WDR) (2 of each type) and 3 for flood
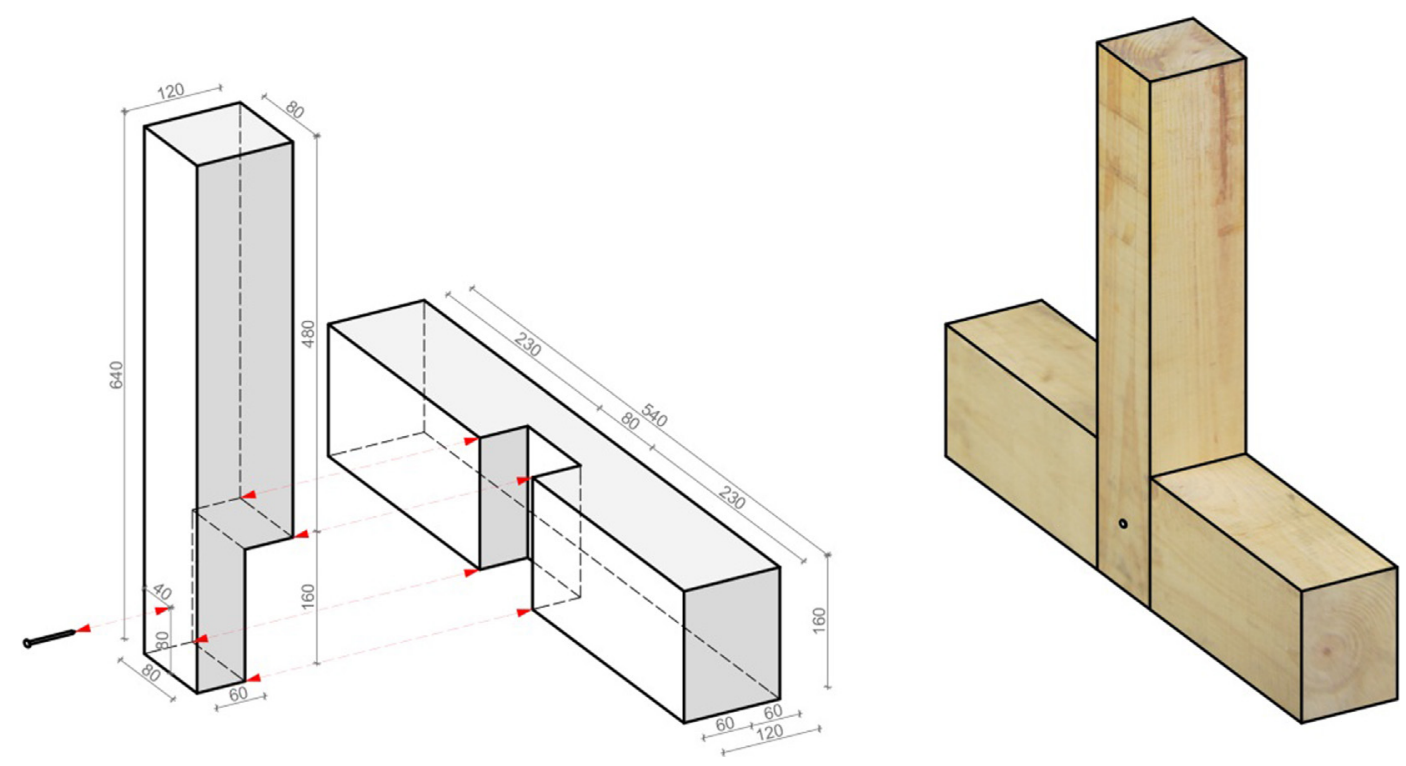

Fig. 4. Unreinforced specimen. 

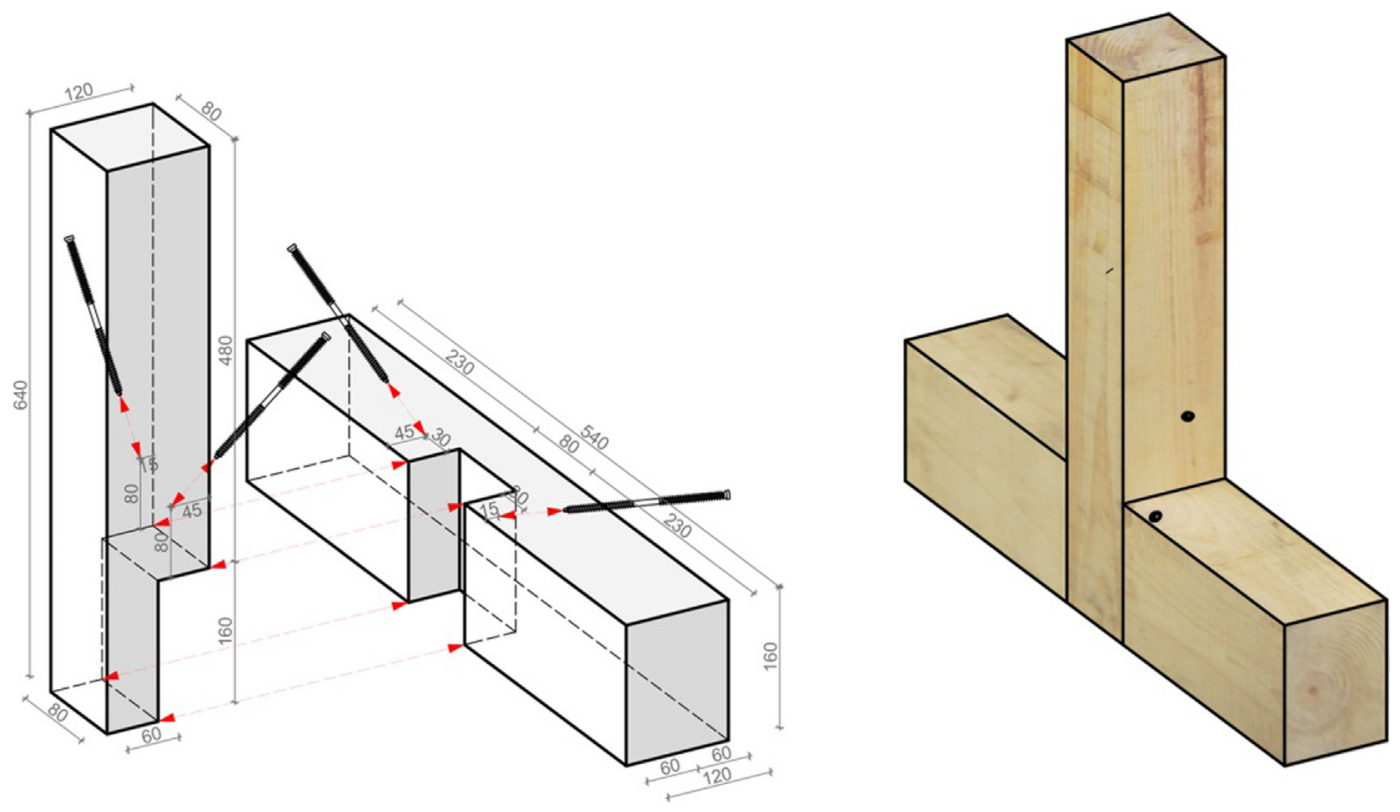

Fig. 5. Specimen strengthened with self-tapping screws.

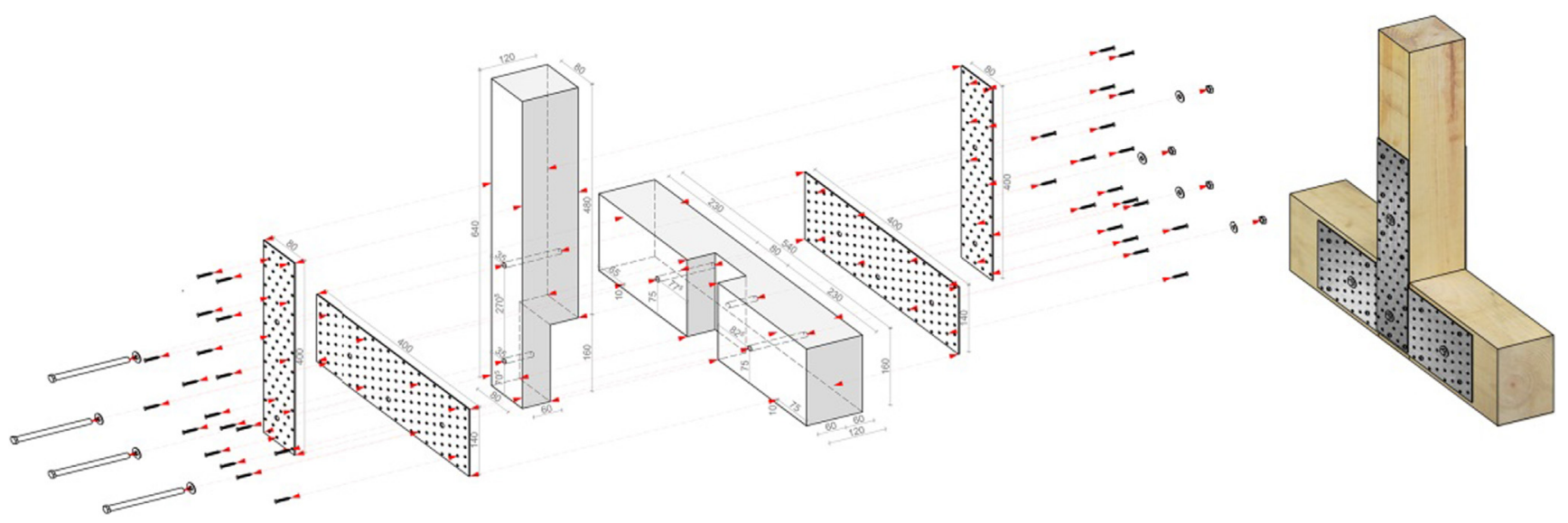

Fig. 6. Specimen strengthened with steel plates.

( 1 of each type). Table 1 summarises specimens denomination, type of weathering and duration.

\subsection{Definition of wetting-drying cycles}

The climate simulations have been designed to replicate real time flood and wind driven rain (WDR) events. The general parameters of the climatic event, such as hourly rainfall and total daily rainfall, temperature, relative humidity, intensity and direction of wind, flood depth and duration were analysed aiming at translating the large scale climate data into the building scale exposure conditions.

The geographic region selected for the weather data input is lower Bavaria due to often recent extreme climate events like the 2006, 2013, June 2016 flood, large number of timber-framed buildings present in the region (Germany, Czech Republic, Austria, Switzerland) and due to availability of free historic weather data from the Deutcher Wetterdienst Climate Data Centre (CDC). For the definition of the periods of rain and flood considered in the experimental campaign, weather data from Germany was initially analysed, more specifically the data from $\mathrm{CDC}$, corresponding to the May-June 2013 Central European flood, where high values of rain were recorded over the Elbe, Rhine and Danube catchments. The data was acquired for the Straubing weather station, which is located North-East of Munchen on the Danube in an area known as the Gäuboden. This is one of the largest loess regions in Germany spreading approximately $15 \mathrm{~km}$ along the Danube. The area has been subjected to many flooding events along the history.

An example of the daily information about the quantity of precipitation, temperature and relative humidity for the rain and flood periods can be seen in Fig. 8. The definition of the number of cycles and the parameters specific for each cycle was carried out taking into account the mentioned data. The model defined in the experimental campaign was simplified to an extent which was considered feasible for the laboratory conditions.

Therefore, the rain cycles were derived from the observed total amount and duration of the precipitation, thus determining an hourly mean amount of precipitation. The determined mean value of $1.1416 \mathrm{~mm} / \mathrm{h}(\mathrm{l} / \mathrm{h})$ corresponding to a light rain intensity according to the Glossary of Meteorology (June 2000) by the American Meteorological Society. Due to hardware limitations, it was decided to apply a factor of 10 to the average value of precipitation 


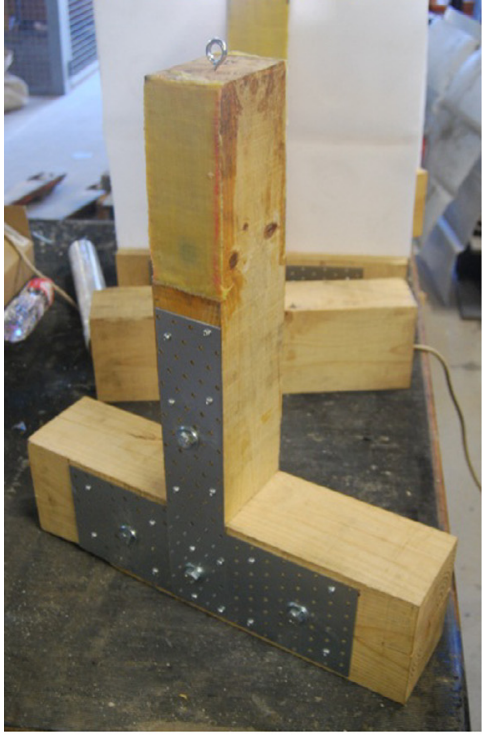

(a)

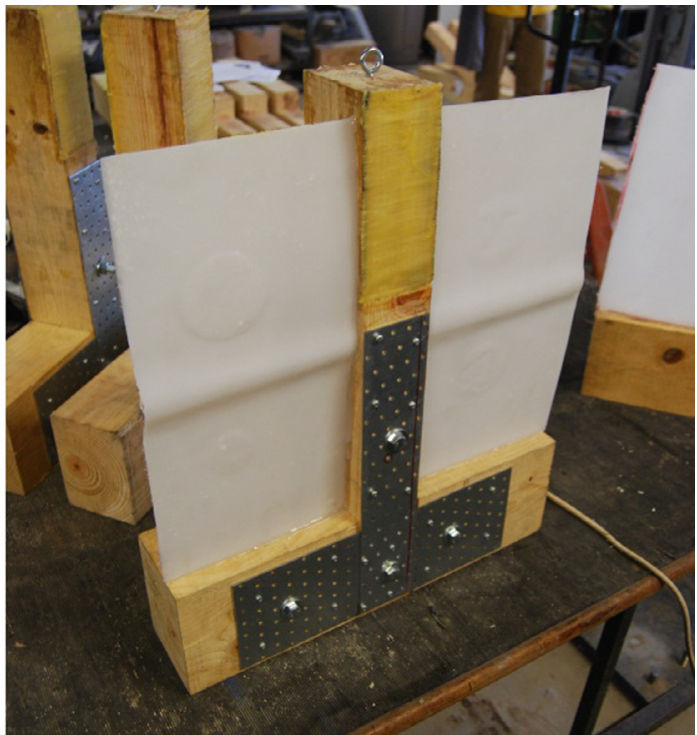

(b)

Fig. 7. (a) Strengthening of gripping zone and (b) positioning of plastic sheets.

Table 1

Specimen denomination.

\begin{tabular}{llll}
\hline $\begin{array}{l}\text { Specimen } \\
\text { denomination }\end{array}$ & $\begin{array}{l}\text { Type of } \\
\text { strengthening }\end{array}$ & $\begin{array}{l}\text { Type of } \\
\text { weathering }\end{array}$ & $\begin{array}{l}\text { Duration of } \\
\text { weathering }\end{array}$ \\
\hline U1 & - & WDR & 54 days \\
U2 & - & WDR & 27 days \\
U3 & - & flood & $4+7$ days \\
P1 & Steel plates & WDR & 54 days \\
P2 & Steel plates & WDR & 27 days \\
P3 & Steel plates & flood & $4+7$ days \\
S1 & Self-tapping & WDR & 54 days \\
S2 & screws & & \\
& Self-tapping & WDR & 27 days \\
S3 & screws & & \\
& Self-tapping & flood & $4+7$ days \\
\hline
\end{tabular}

previously calculated. Therefore, the final amount of precipitation used is $12 \mathrm{l} / \mathrm{h}$, which corresponds to a heavy rain intensity.

The daily Wind Driven Rain program consists of a four-hour wind driven rain period followed by a four hour drying period. This procedure was repeated 108 times (27 days) followed by a 7 days drying period, see Fig. 9a. For the flood cycle (Fig. 9b), it was decided to consider the same raining and drying base cycle as the one adopted for the wind driven rain, repeated for 4 days. After this, the connections were submerged for 7 days, after which a drying period of 7 days was implemented.

\subsection{Test setup}

A new test setup was designed to simulate the weathering of the timber connections either subjected to wind driven rain or to a flood (Fig. 10). The timber connections were positioned in reused IBC tanks with a $1000 \mathrm{l}$ volume. The water is transferred from the tanks to the spray nozzles through an upstream hydraulic system composed of a water pump, 3/4 PVC pipes, flexible hose for the pump connection and brass accessories. The pump is connected to an uptake pipe and to a Tee connector spreading the water output in two: (1) the first part is composed of an L shape horizontal pipe which is linked to a system of three $S$ shape brass connections and the nozzles; (2) the second one consists of a valve and pressure

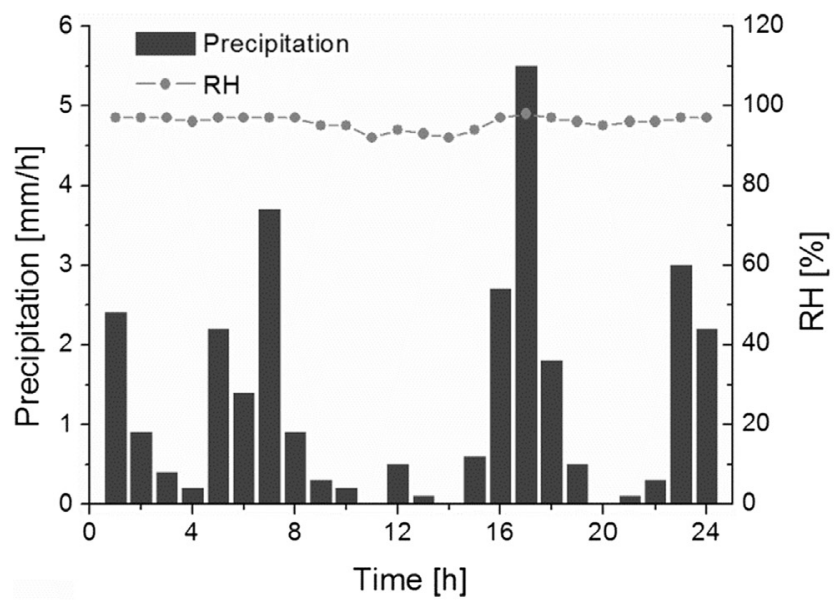

(a)

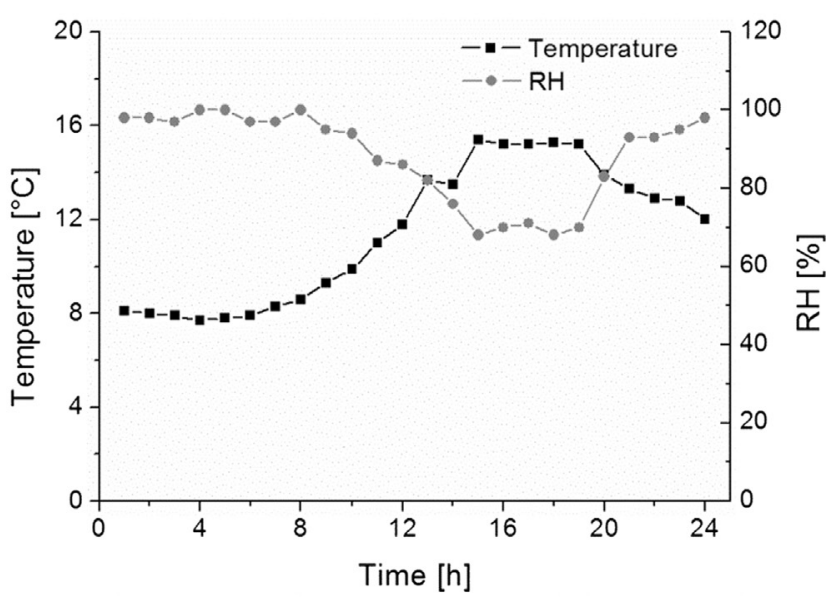

(b)

Fig. 8. Sample daily hourly cycle: WDR (left), flood (right). 


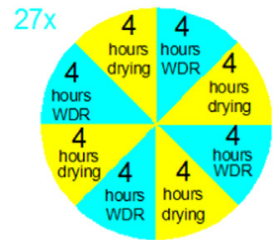

(a)

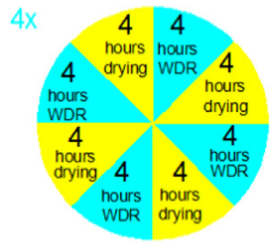

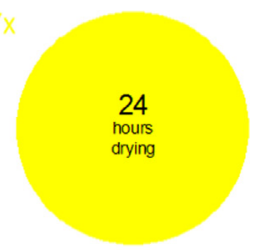

(b)

Fig. 9. Cycles adopted: (a) Wind Driven Rain; (b) Flood.

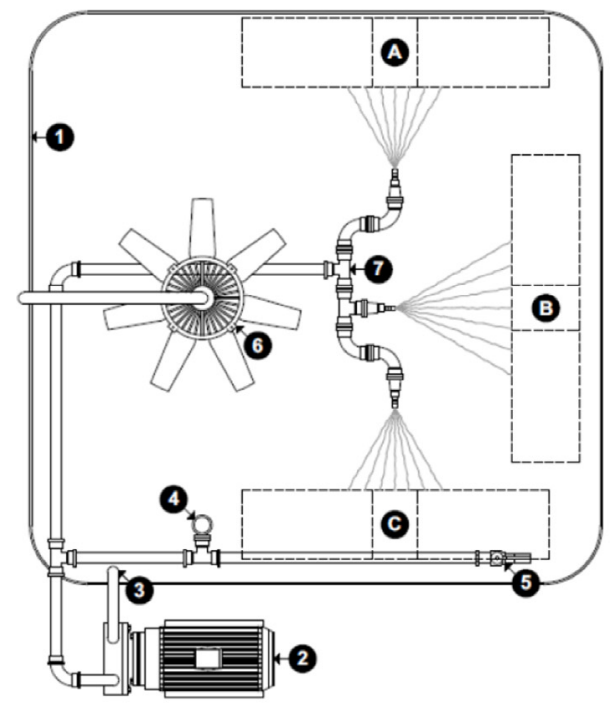

(a)

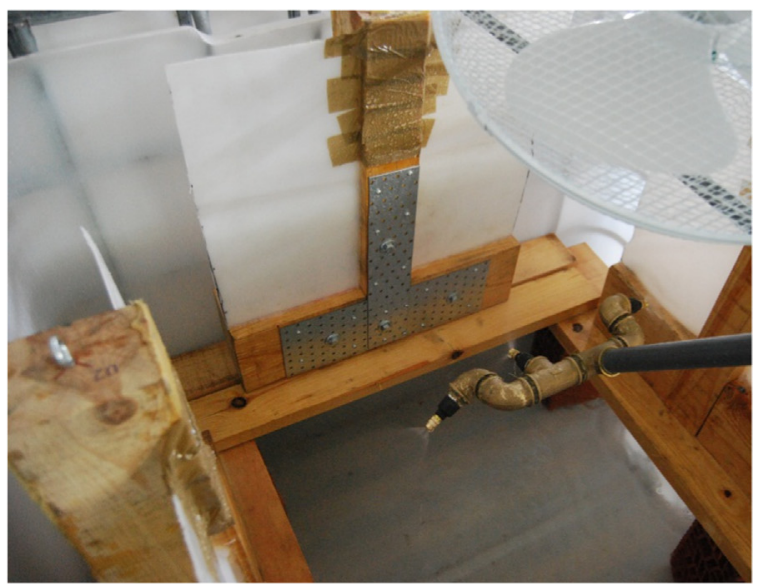

(b)

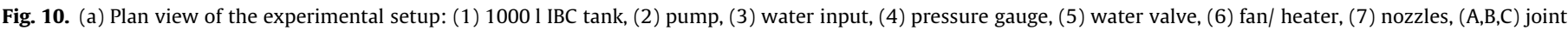
samples; (b) laboratory test setup.

gauge. In each $\mathrm{S}$ shape brass connection, the angle can be adjusted in two directions. For each system a strainer filter and a water pump filter was added to prevent the nozzles from clogging with impurities. By closing or opening the valves, the pressure in the system increases or decreases, leading to a water output from $10 \mathrm{l} / \mathrm{h}$ to $15 \mathrm{l} / \mathrm{h}$ for each nozzle. The water valve was adjusted in this case to have a 0.8 bar pressure in the hydraulic system so that the output water in each nozzle was $12 \mathrm{l} / \mathrm{h}$.

The adjustable spray's diameter from the commercial spray nozzles was set at approximately $300 \mathrm{~mm}$, positioned at a $45^{\circ}$ angle regarding the timber connection. It should be mentioned that each tank works in a closed loop circuit: they serve as water reservoir and thus the water pumped through the nozzles and respectively the output valve is being drained back in the tank.

At the top of the tank an oscillating fan was mounted so that the circulated air will reach all three samples. After running the test for a period of time, it was observed that the fan doesn't enhance enough the drying conditions. Therefore, a $1000 \mathrm{~W}$ portable heater was added to each tank to obtain to the drying parameters needed.

The joint samples (A, B, C) are collocated on top of a timber plank, in order to simulate the presence of a foundation, so that water does not flow freely.

\section{Evolution of specimens during wet and dry cyclic tests}

\subsection{Monitoring procedures}

The specimens were monitored during all the stage of the wetting and drying periods in terms of relative humidity $(\mathrm{RH})$, temperature and weight of the specimen, which gave an indication of the water absorption of the same.

The cycles of wetting (wind driven rain) and drying, were controlled in an automatic way through a LabVIEW software. For the monitoring process, a load cell was connected to the joints aiming to record in a continuous way the variation in weight across the wetting and drying periods.

Four environmental moisture and temperature sensors were mounted in the WDR tanks. Additionally, one temperature and moisture sensor was placed outside of the tanks to record the air relative humidity and temperature in the laboratory. These measurements were taken in order to observe if any influence of the external environment conditions occur in the drying process. An average temperature of $22^{\circ} \mathrm{C}$ was measured inside the tank, while outside the average temperature was above $25^{\circ} \mathrm{C}$. Average humidity during drying cycles was $35 \%$, while it reached $90 \%$ during wetting cycles.

A daily control program was set to observe and try to determine the water absorption rate in the post and to observe the patterns of water migration through the joint. Daily data was acquired by measuring the moisture content of the timber at a depth of $20 \mathrm{~mm}$ in different positions.

\subsection{Weight history}

Two distinct sequences can be observed in the weight history diagrams of the samples. In the first sequence, the weight increases (upward trend) in a cumulative way during the wetting periods and only part of the weight increment is lost in the drying period, 
see Fig. 11. This is associated to the insufficient drying power of the fans (left part of the diagram). In the second sequence (central part of the diagram), it appears that the weight gains during the wetting period are compensated by the loss of weight during the drying period.

This behaviour is associated to the influence of the heater added in the tanks, meant to enhance the drying conditions. Except for the first wetting cycle, which consists in a $450 \mathrm{~g}$ water intake for the timber sample, most of the wetting cycles describe a regular water intake varying from $30 \mathrm{~g}$ to $170 \mathrm{~g}$ per wetting cycle with an average of $121 \mathrm{~g}$ per cycle.

It has to be pointed out that for all specimens subjected to WDR the weight recorded at the end of the final drying period of 7 days approximately reach the values recorded initially (12\%) at the beginning of the weathering cycles (Table 2). It can be concluded that the samples approximately returned to the initial moisture content after the drying period before undergoing the mechanical testing. The same can be said for the flood samples.

\subsection{Water migration during cycles and at final drying}

Based on visual observation and taking into consideration the moisture in the post by measuring its moisture content, a diagram of the moisture zones was drawn on the connection's wetting evolution as shown in Fig. 12. The four zones identified correspond to the progression of the moisture front at each of the four hours of the wetting cycle for the specimens submitted to WDR. It was observed that in the first hour of the test only the directly exposed part of the post would get soaked, given that the plastic sheets act as a barrier. The position of the heartwood in relationship with the section of the beam also influenced the pattern of water propagation, having a slower rate in the heartwood than in the sapwood. The presence of a timber bedplate support also facilitated the
Table 2

Initial and final weight of specimens.

\begin{tabular}{llll}
\hline $\begin{array}{l}\text { Specimen } \\
\text { denomination }\end{array}$ & $\begin{array}{l}\text { Initial weight } \\
{[\mathrm{kg}]}\end{array}$ & $\begin{array}{l}\text { Weight after } \\
\text { weathering }[\mathrm{kg}]\end{array}$ & $\begin{array}{l}\text { Final weight } \\
{[\mathrm{kg}]}\end{array}$ \\
\hline U1 & 10,00 & 11,46 & 9,78 \\
U2 & 9,38 & 11,56 & 9,48 \\
U3 & 9,86 & 12,36 & 10,26 \\
P1 & 13,01 & 15,42 & 13,42 \\
P2 & 12,44 & 14,40 & 12,62 \\
P3 & 12,38 & 14,98 & 13,02 \\
S1 & 10,1 & 10,98 & 9,56 \\
S2 & 9,57 & 11,7 & 9,62 \\
S3 & 9,90 & 12,10 & 10,18 \\
\hline
\end{tabular}

** Before weathering.

** After drying.

water sorption at a faster rate from the bottom of the beam due to the permanent presence of water. This is a hypothesis that corresponds to what can actually be found in practice.

Water present behind the plastic sheets could be observed in small amounts only at the end of the wetting cycle, as absorption in the perpendicular direction to the wood grain has a very slow rate of propagation. In addition, as the plastic sheets work as barriers, it was clear that the moisture propagated from the bottom part of the post in contact to the wood beam. In fact, the water migration through the post presented two distinctive patterns. The predominant pattern consisted on water migration through the post alongside the wood grain and the other pattern consisted in water migration from the beam to the post by direct contact. The latter pattern is strictly dependent on the joint quality between the top surface of the beam and the post. Therefore, a direct correlation between the gaps present in the joint and presence of water in the measured points was observed. Most of the points where a high moisture level was present correspond to a tight connection

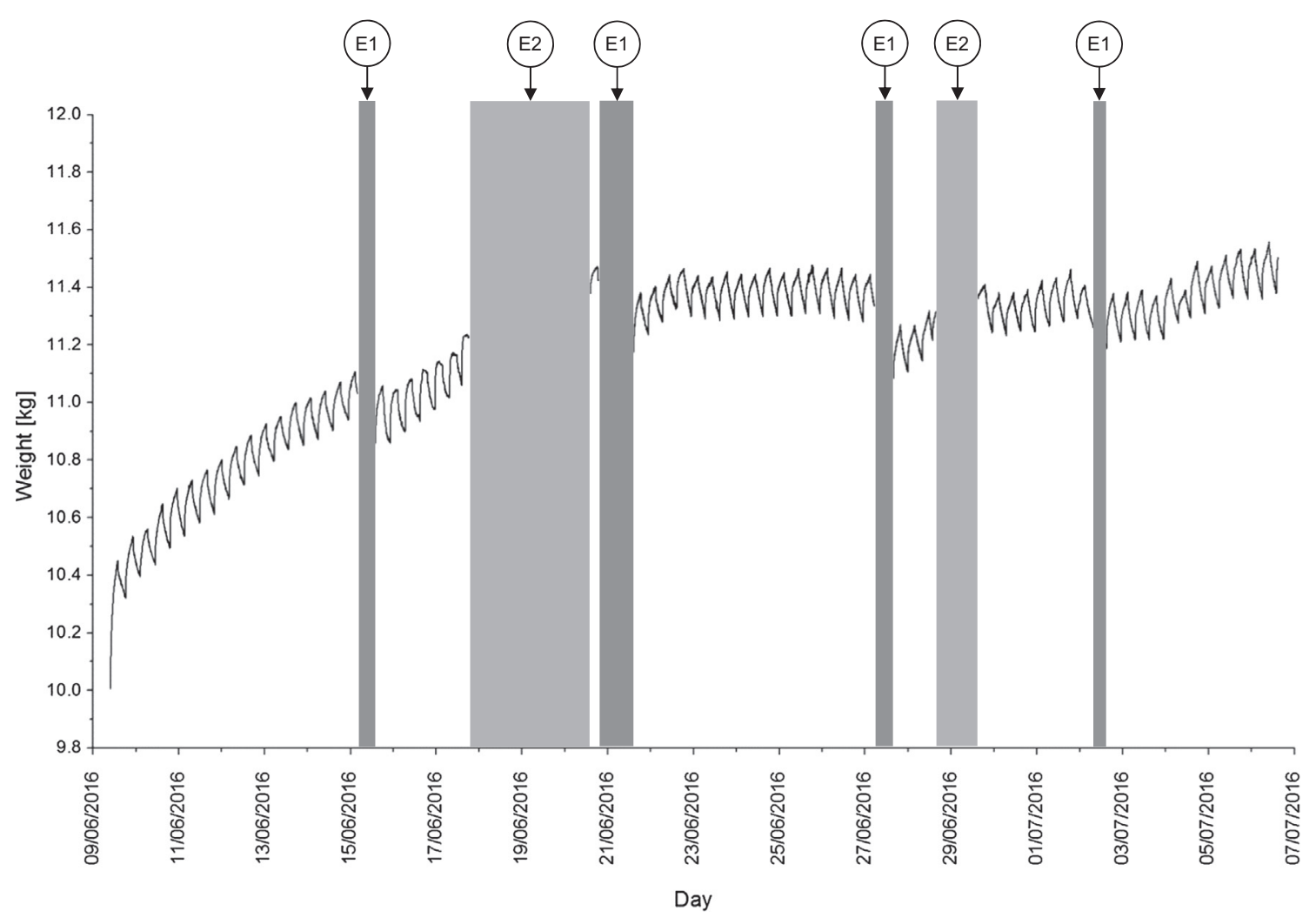

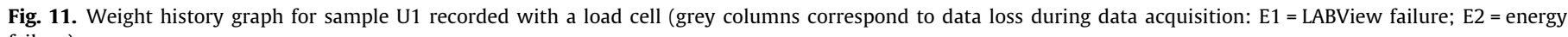
failure). 


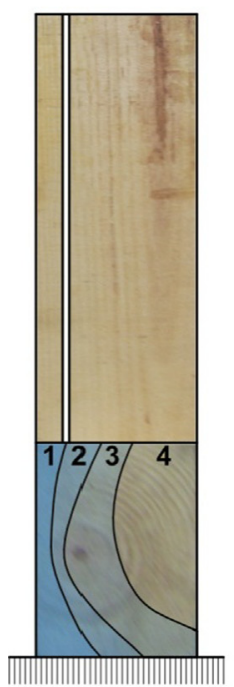

(a)

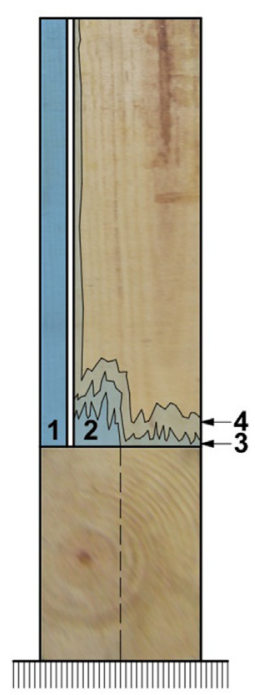

(b)

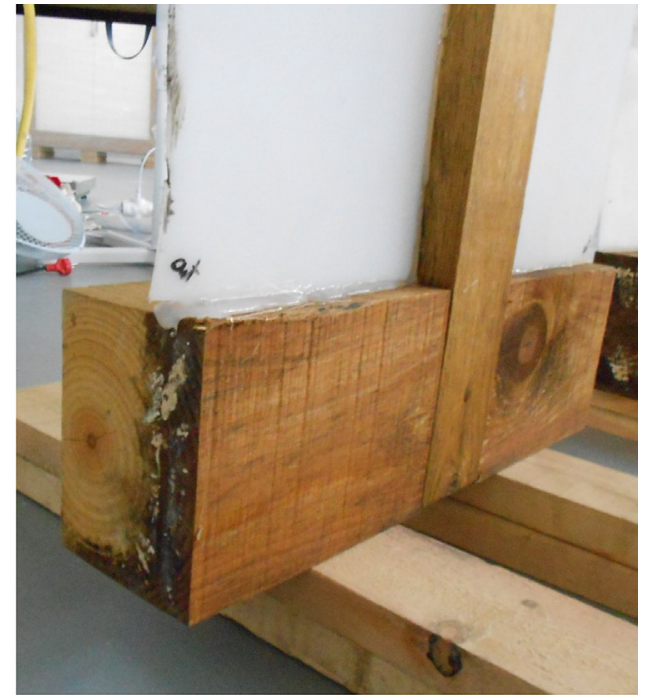

(c)

Fig. 12. Qualitative water sorption diagram: (a) beam; (b) post; (c) real specimen.

between the post and beam thus facilitating a higher rate of moisture transfer.

At the end of the wetting/drying cycles, fungi grew on the joints, particularly for those subjected to the longer wetting/drying period, see Fig. 13. Additionally, the metallic elements started to rust: the nail in the case of the unreinforced connection, the drive from the screws head in the double threaded screws reinforced connection and regions of the pre-drilled holes in the steel plates in the reinforced connection.

Finally, the water migration in the specimens was assessed in a qualitative way through the thermal images taken using a thermal imaging camera (FLIR-T62101) during the final drying period of 7 days. Infrared technology allows to instantly visualise the thermal condition of an object, allowing in this case to correlate the different temperatures registered with the water content in the joint. A lower temperature indicates a higher $\mathrm{RH}$ in that zone.
Observing the thermal images of the specimens at the beginning of the final drying period (Fig. 14), it is immediately noticeable the difference between the specimens subjected to flood and those subjected to WDR. The flood specimens absorbed water in a uniform way, being submerged constantly in water, whereas WDR specimens have an accumulation of water in the post-beam interfaces, as the water enters through the gaps that are inevitably present in carpentry joints, and at the bottom of the beam where the support was located, making the migration of water to the exterior during the drying process more difficult.

Already after $24 \mathrm{~h}$ of drying and $48 \mathrm{~h}$ of drying (Fig. 15) differences could be noted in the temperature distribution of the specimens, therefore in the moisture content. The importance of the joints in the drying process is even more evident in this phase due to the accumulation of water in this region.
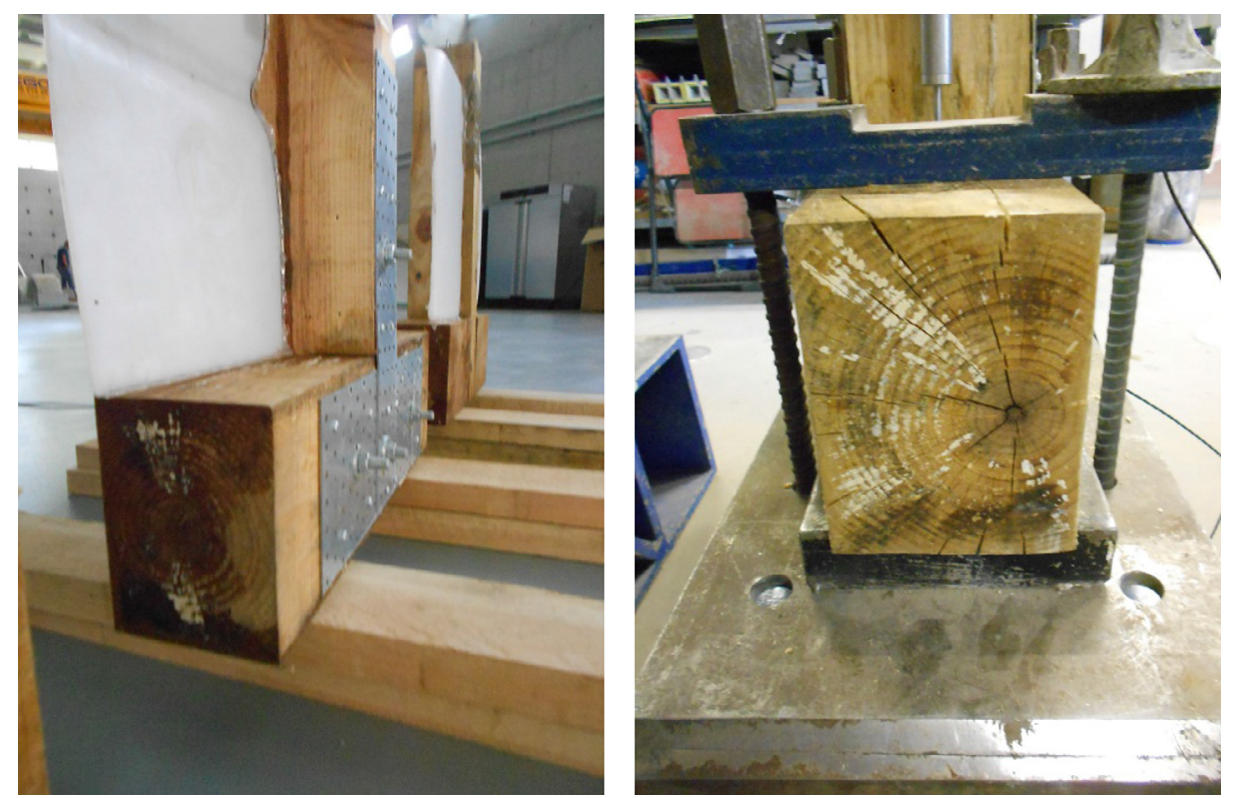

Fig. 13. Development of fungi: wet condition (left), after drying (right). 


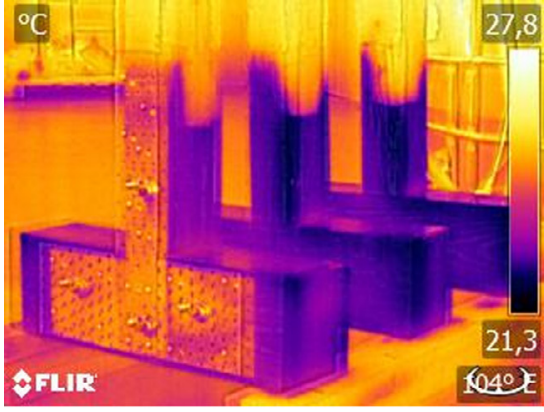

(a)

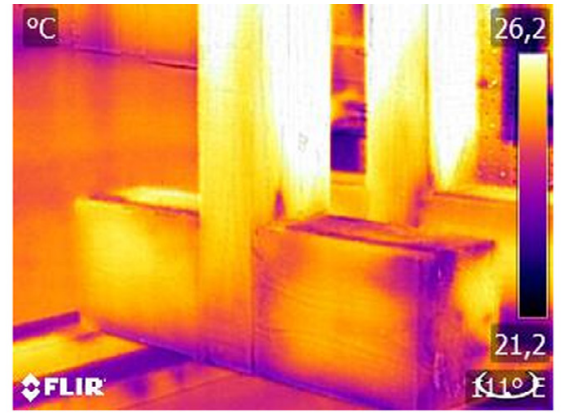

(b)

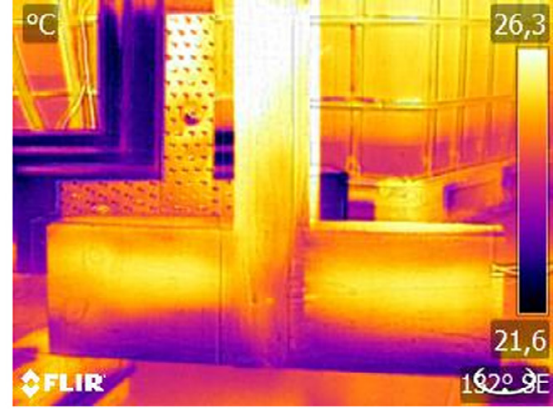

(c)

Fig. 14. Infrared image of the connections at the beginning of the drying period: (a) connections subjected to flood cycles; (b) (c) connections subjected to WDR cycles.

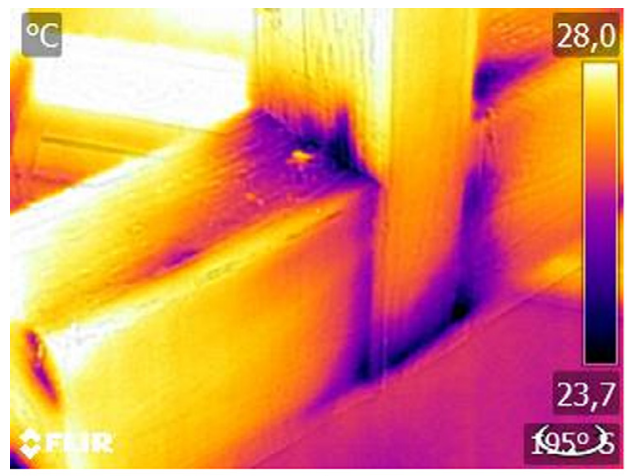

(a)

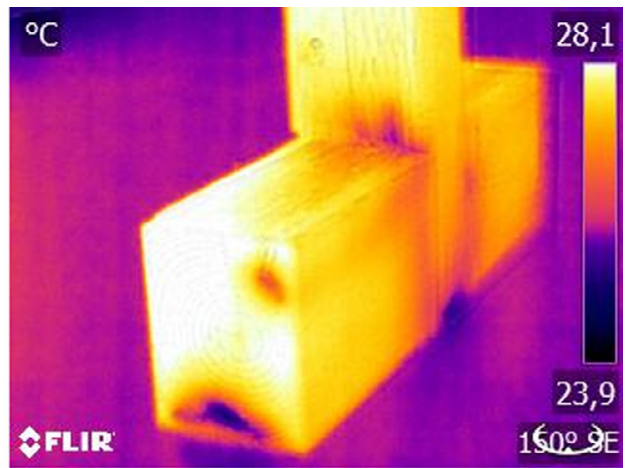

(b)

Fig. 15. Infrared image of double threaded screws reinforced connection subjected to WDR cycles (a) after $24 \mathrm{~h}$ and (b) $48 \mathrm{~h}$ of drying.

Another factor that should be taken into consideration is the "scale" effect regarding the hygroscopic property of wood. In the case of the joints of this study, the cross-section is small enough that water adsorption and the effects on swelling/shrinkage of the elements are relatively fast. After the wetting/drying cycles, shrinkage fissures were observed in the specimens. Moreover, torsion of the cross section was observed. This deformation did not affect the mechanical tests on joints, but it could potentially have a negative effect on a larger scale, e.g. the in-plane shear capacity of a timber-framed wall could be affected by buckling.

The results here presented are specific to this joint, which has dimensions which are typical for carpentry joints encountered in Pombalino buildings. Clearly, changing the elements' size will affects the consequences of an extreme event.

\section{Pull-out tests on weathered traditional joints}

Joints are the most sensitive part of a timber structure and they constitute the structural element that ultimately controls the dissipative capacity of the structure in case of an earthquake, but also the general structural performance. Because of this, it was chosen to only analyse the behaviour of the joints after weathering, without having to test a whole wall.

\subsection{Reference tests and setup}

As mentioned above, the mechanical tests performed here are a replica of pull-out tests carried out on sound half-lapped joints typical of Pombalino buildings [34]. The unreinforced joints tested by Poletti et al. [34] will serve as a reference for the evaluation of the performance of the weathered specimens.

The test setup and the cyclic procedure (Fig. 16a) adopted for the test were also in accordance to the tests performed on the sound specimens. The tests setup consisted of a steel beam to which the beam of the joint was anchored, a steel frame to which a load cell with a capacity of $150 \mathrm{kN}$ was connected and a gripping device connecting the specimen to the actuator and load cell. The cyclic procedure (Fig. 16b) presents repetition cycles for the stabilisation of the specimen. The loading protocol adopted was the same used for the sound specimens [34] and it is based on standard EN 12512. A preliminary monotonic test was carried out in order to obtain the yield and ultimate displacement. The protocol was maintained the same for comparison purposes. Pull out displacements were measured with LVDTs (Linear Voltage Displacement Transducers), namely the vertical uplift of the post, the out-ofplane opening of the half-lapped connection and the uplifting of the beam from the steel beam (see [34]).

\subsection{Analysis of results}

The results of the pull-out tests are here analysed in terms of load-uplift curves, failure mechanisms and seismic parameters, namely initial stiffness and energy dissipation, and are then compared to the results of sound specimens obtained from previous tests [34].

\subsubsection{Load-uplift diagrams and damage patterns}

4.2.1.1. Unreinforced specimens. The pull-out results on unreinforced specimens are highly dependent on the quality of the connection, in particular on the presence of gaps at the joint interfaces between the post and the beam. In fact, a looser connection, therefore with more gaps, could lead to a lower capacity of the same. Since only a limited amount of specimens is available, these results should be seen with caution but they give an idea about the influence of weathering in the connections. In general, the joints did not present excessive gaps before weathering (never 


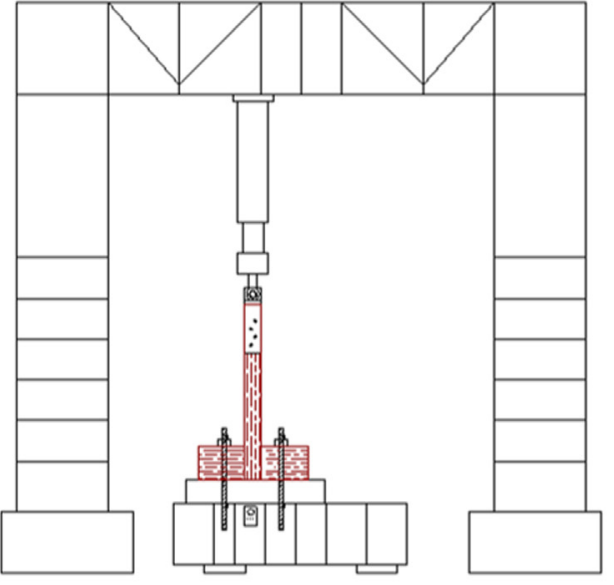

(a)

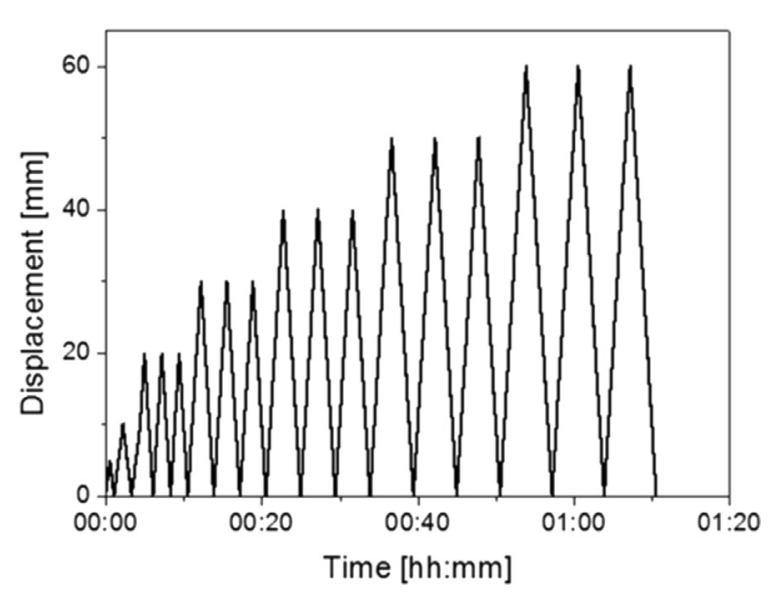

(b)

Fig. 16. (a) Test setup and (b) procedure adopted for the pull-out tests (adapted from [34]).

above $1 \mathrm{~mm}$ ), contrary to what happened in previous experimental campaigns [34].

Fig. 17 shows the of pull-out diagrams in terms of load-uplift for all unreinforced joints. The response is characterised by an out-ofplane opening of the post when it is being pulled out and by the plastic deformation of the nail when released, see Fig. 18. The connection stopped working when the nail was not effective, as it pulled out completely from the beam. This behaviour is compatible with what was observed for sound specimens [34]. All specimens present high initial strength with an early non-linear behaviour. Strength and stiffness degradation are important for all specimens. When comparing the three weathered specimens, it is seen that all 3 specimens have a similar initial stiffness, with specimen U2 slightly lower. In terms of maximum load capacity, it appears that the prolonged exposition to WDR led to a higher lowering in the resistance (U1) representing a worse environment condition when compared to flood (U3). It would therefore appear that the wetting/drying cycles are more demanding on the joints than the flood event. U2 in general presents better results compared to U1, but it encountered an early pulling out of the nail with subsequent loss of the LVDT, as it can be deduced by the out-of-plane opening of the post (Fig. 18).

Comparing the weathered specimens with the sound ones (Fig. 17b), it is stressed that the results depend greatly on the

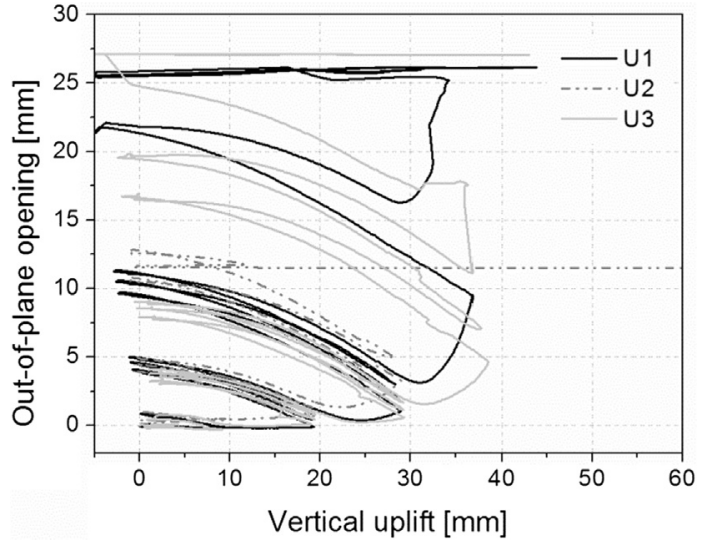

Fig. 18. Out-of-plane opening of joints.

quality of the unreinforced joint in terms of maximum load. However, in all cases, the initial stiffness is slightly higher for sound specimens. There is a wide range of results for sound specimens due to the large gaps present for some of those specimens. For the weathered specimens, this did not occur, thus results were nearer.

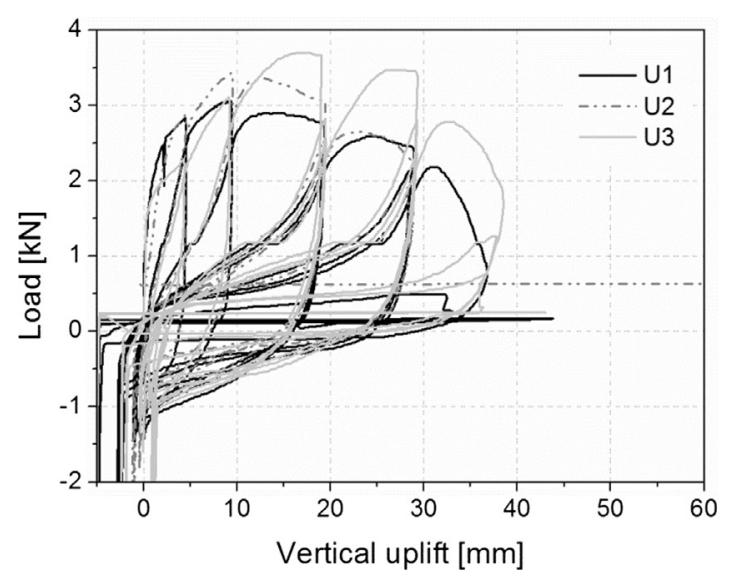

(a)

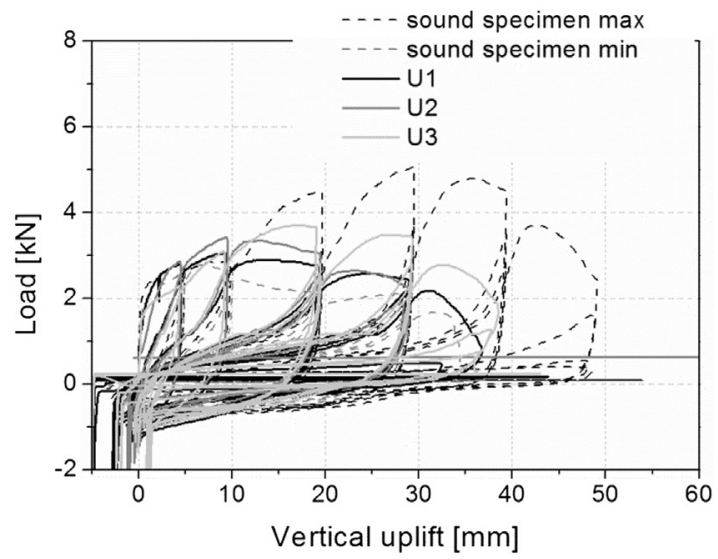

(b)

Fig. 17. Load-uplift curves: (a) comparison among weathered specimens; (b) comparison among sound and weathered specimens. 
In terms of failure mechanisms, all joints failed due to the pulling out of the nail (Fig. 19). The nails presented a plastic deformation and all appeared rusted after being subjected to wet conditions. Additionally, the interface between post and beam appeared moist to the touch, even though the difference of weight before and after drying was only of $1 \%$ for WDR specimens and $4 \%$ for flood [35].

4.2.1.2. Specimens strengthened with steel plates. In case of steel plates, initial gaps play a minimal role in the response of the joints, since the plates tighten the joints effectively nullifying the presence of gaps. Moreover, steel plates avoid any out-of-plane opening, as the bolts through the thickness of the joint securely connect post and beam.

Among the weathered specimens, it is evident that P1 observed greater strength and stiffness, recovering more its original capacity

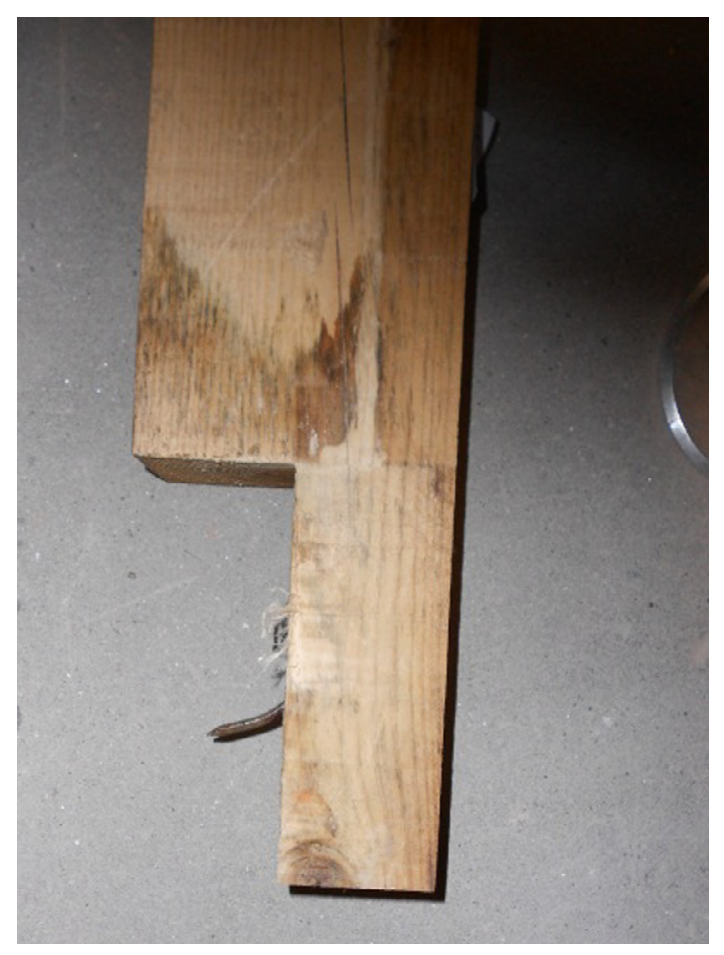

Fig. 19. Typical failure due to nail pull-out: plastically deformed nail.

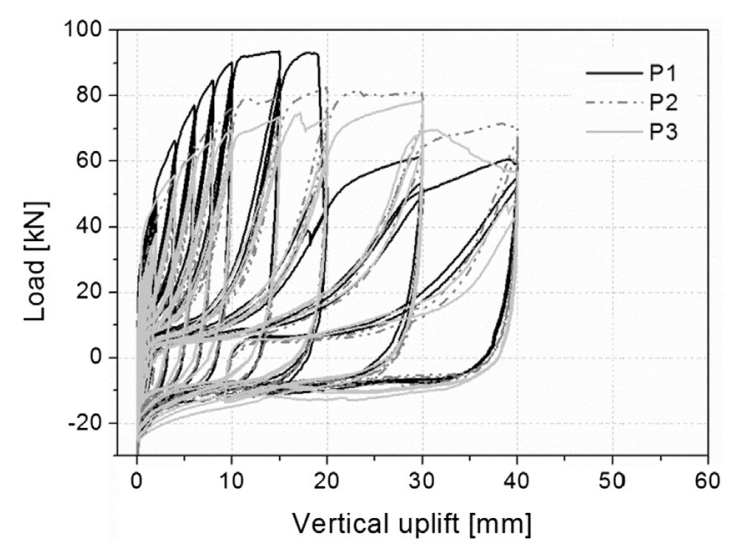

(a) when compared to the sound specimen (Fig. 20b). While P1 was subjected to a higher number of wetting cycles, P1's drying period was characterised by higher room temperature in lab, thus allowing for an even drying of the specimen with steel plates. Notice that steel plates block humidity inside, making the drying process more time-consuming and ineffective. In any case, any of the exposure conditions results in the lowering of the load corresponding to the pull out of the post from the beam in relation to the reference specimen, achieving a decrease of $30 \%$ for unreinforced specimens, $31 \%$ for steel plate specimens and $11 \%$ for self-tapping screws.

One interesting feature of the reinforced weathered connections is the occurrence of a smoother post peak range when compared to the reference specimen. In case of weathered connections, the residual strength associated to the ultimate uplift displacement is higher. This can be associated to the failure pattern observed for the different specimens (Fig. 21). For sound specimens, the total rapture of the plate was observed [34], whereas in the three weathered specimens the steel plates buckled but did not fail. It is considered that the buckling load of the steel plates should be lower than the tensile strength, justifying thus the load strength of the connections. In addition, since the joint was not completely dry internally in the half-lap, it allowed for a higher deformability when compared to the reference specimen. The moist condition of the connection was confirmed after testing by using a pin moisture meter on the internal surfaces of the joint. Values of $15-16 \%$ surface moisture were measured on the sides of the half lap, while on the main surface of the half lap where the nail is applied and the post and beam are in contact, the values of moisture content exceeded the fibre saturation point of wood, indicating that the drying process was effective on the surface of the joint, but could not effectively dry the inner contact surfaces.

4.2.1.3. Specimens strengthened with self-tapping screws. In opposition to what was observed for steel plates, self-tapping screws did not apparently suffer from the wetting drying cycles. Strength and stiffness of weathered specimens were very similar to those observed for sound specimens (Fig. 22). The way in which these screws are applied (no pre-drilling and very tight fitting) allowed for a minimal water penetration. Moreover, since the screws also closed the gaps present, these did not influence the results. It is important to note that in these connection the effect of the nail is negligible, being controlled mostly by the self-tapping screws.

In terms of damages (Fig. 23), little damage is visible, mainly cracking of wood at the joint of the screw between post and beam. Horizontal cracks at the beam along the grain are also visible. These result from the pulling-out of the screw.

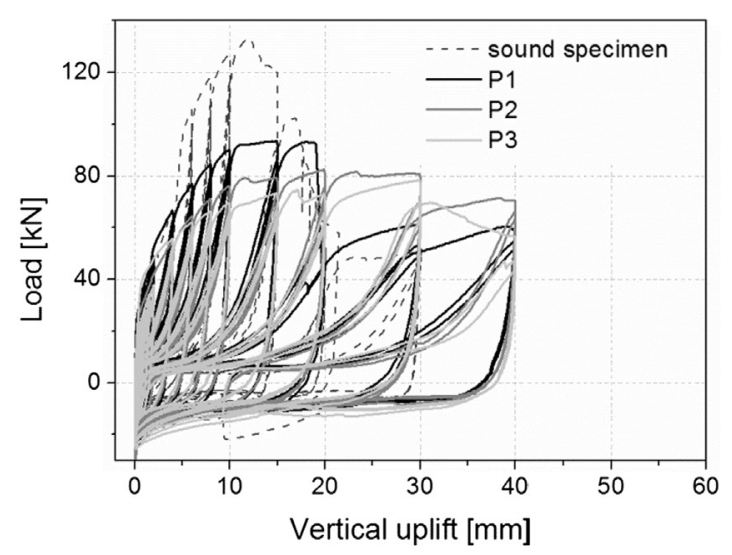

(b)

Fig. 20. Steel plates results: (a) weathered specimens; (b) general comparison. 


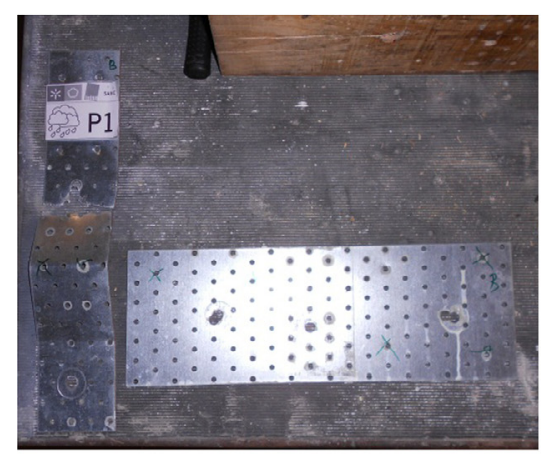

(a)

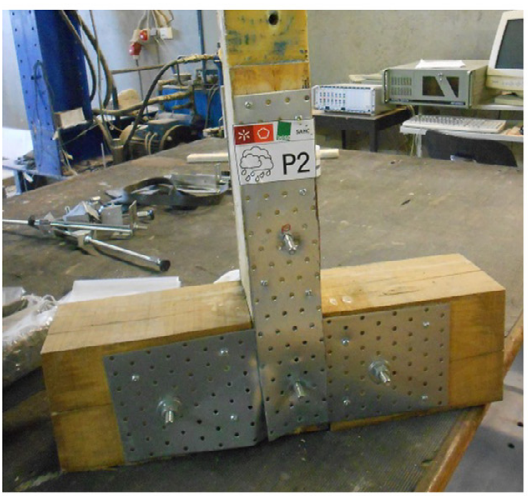

(c)

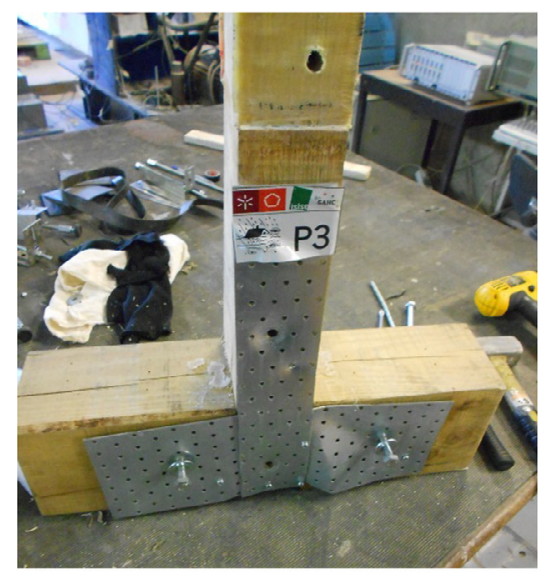

(e)

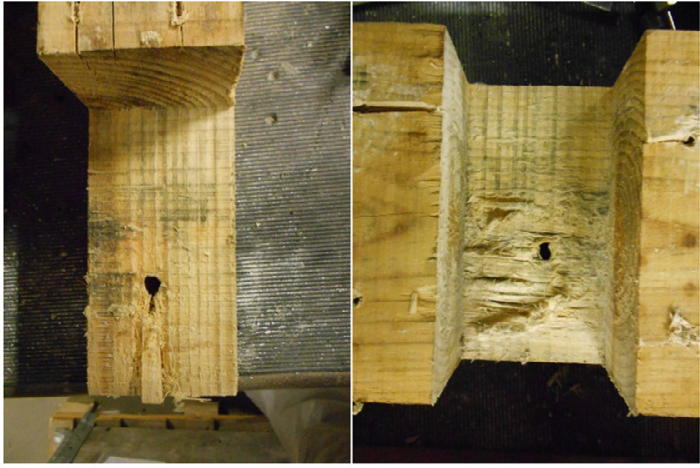

(b)

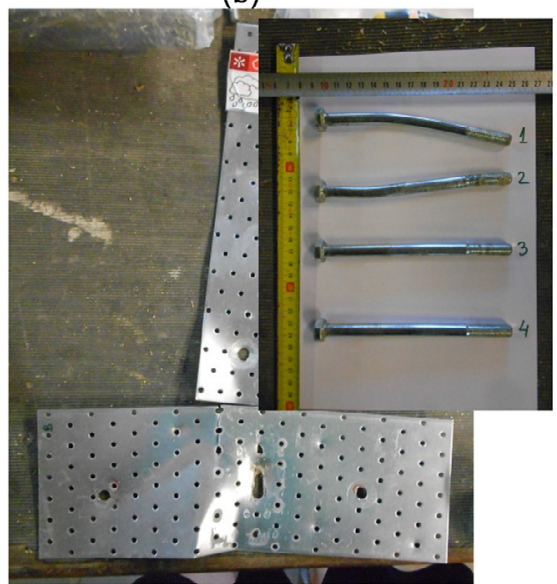

(d)

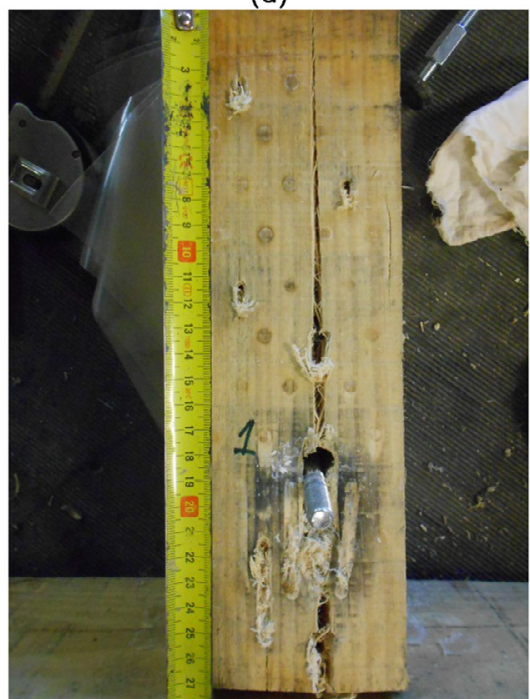

(f)

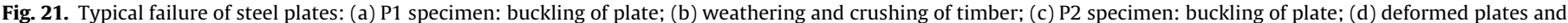
bolts; (e) P3 specimen: buckling of plate; (f) cracking of timber.

\subsubsection{Parameters for the seismic assessment of joints}

To better compare the evolution of the joints after weathering, parameters commonly used for the seismic assessment, such as stiffness degradation, energy dissipation and viscous damping, were compared to those obtained for sound specimens.

4.2.2.1. Stiffness degradation. Cyclic stiffness is calculated for each cycle as the slope of the line connecting the origin with the point of loading corresponding to the maximum displacement. The overall cyclic stiffness presents a steep degradation for early vertical uplifts, see Fig. 24. The stiffness degradation is very close for all unstrengthened weathered specimens. The trend fits inside the range of the sound specimen results and it is nearer to the weakest sound connection. This shows that weathering of unreinforced joints leads to degradation of the joint, namely the appearance of gaps that cause this stiffness degradation. The appearance of gaps for this type of joint causes a loosening of the joints, thus a significant loss in stiffness.

The weathered specimens with steel plates present similar stiffness recorded in the sound specimens with a slight decrease for 


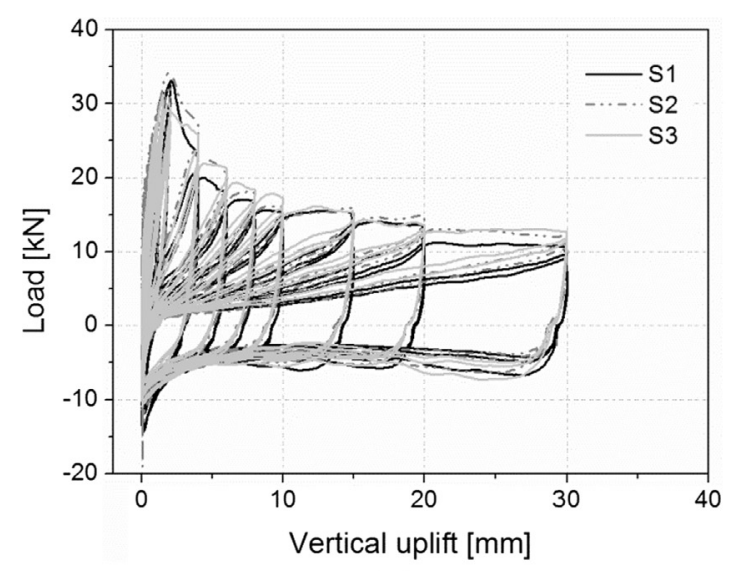

(a)

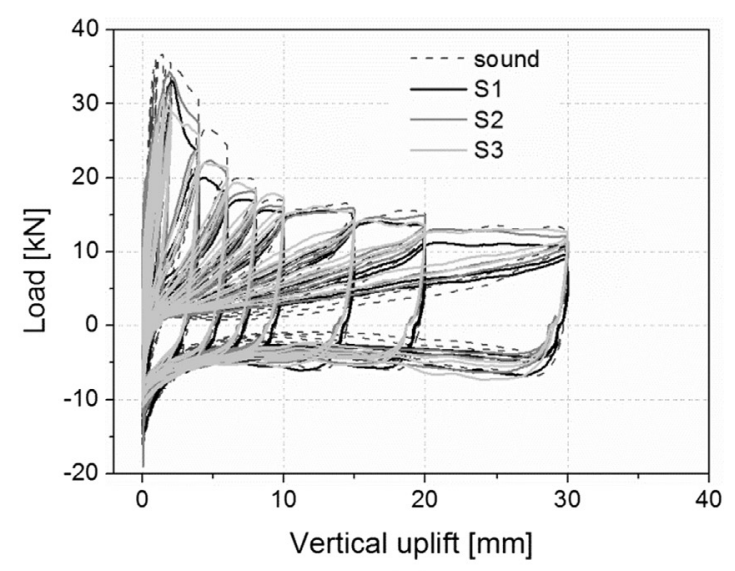

(b)

Fig. 22. Self-tapping screws: (a) weathered specimens; (b) general comparison.
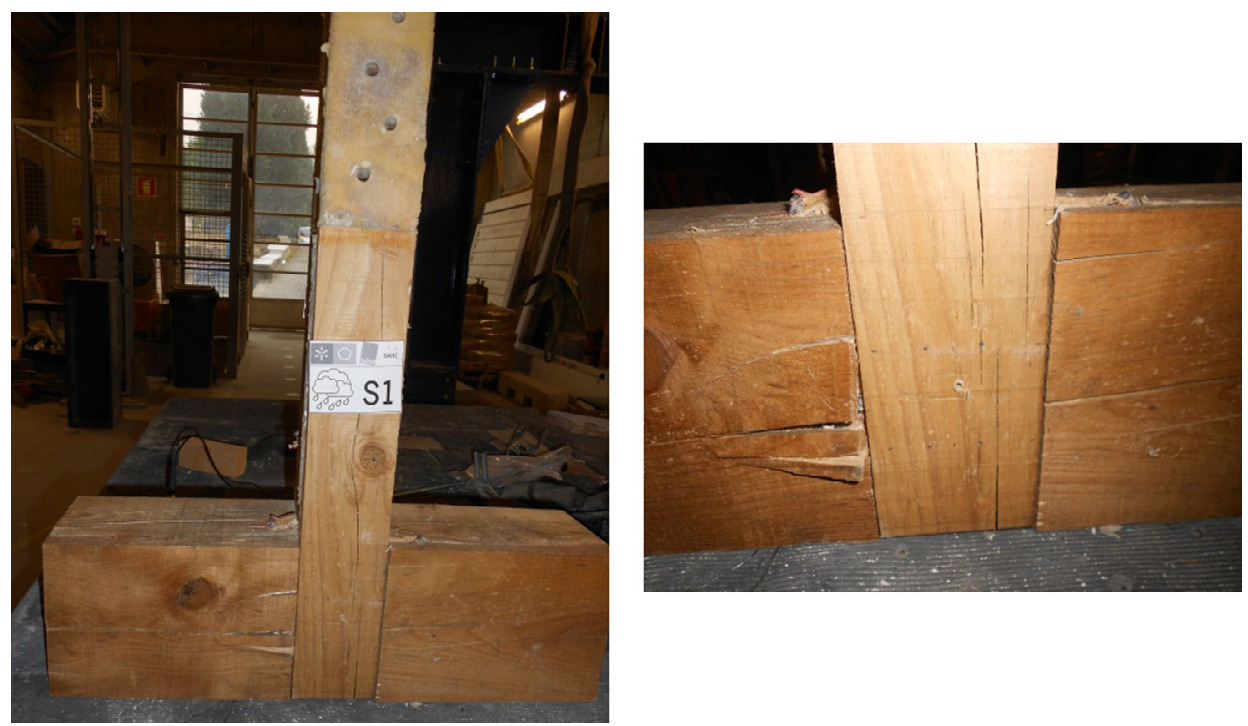

Fig. 23. Typical failure for self-tapping screws.

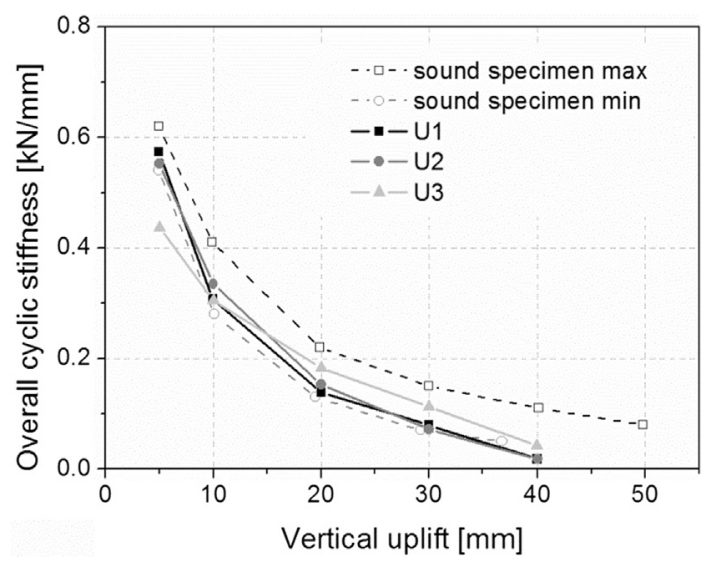

Fig. 24. Stiffness degradation: unreinforced specimens.

higher values of uplift, but overall the differences can be considered negligible. The difference is even less for specimens retrofitted with self-tapping screws for the same reasons mentioned when comparing the hysteretic results. With appropriate drying, it seems to be possible to recover the capacity of these joints (Fig. 25).
4.2.2.2. Energy dissipation. It is observed that joints have a great dissipative capacity, which is attributed to the connectors. Each connector presents a different dissipative capacity, from weak (nail) to strong (plates or FRPs). Considering the unreinforced specimens, the three weathered specimens presented very similar results in terms of dissipated energy (Fig. 26a), once again confirming the good quality of the specimens. When compared to the sound specimens, the dissipated energy fell inside the range of the results for sound specimens, but almost coincident to the lower bound associated to the connection with high initial gaps (Fig. 26b). This is due to the fact that wetting/drying cycles led to the appearance of larger gaps, comparable to those of the weakest joints of the sound specimens. This is particularly disadvantageous for half-lap joints and for this particular mechanical test, as the loosening of the joints causes a loss in stiffness and dissipative capacity. This is also in accordance to what observed by Bradley et al. [4]. This, however, does not mean that gaps are always to be avoided, as for some joints in existing timber structures slips are allowed and are beneficial to their seismic performance. However, in this study the comparison is made between sound and weathered specimens, where gaps were not beneficial, and in gen- 

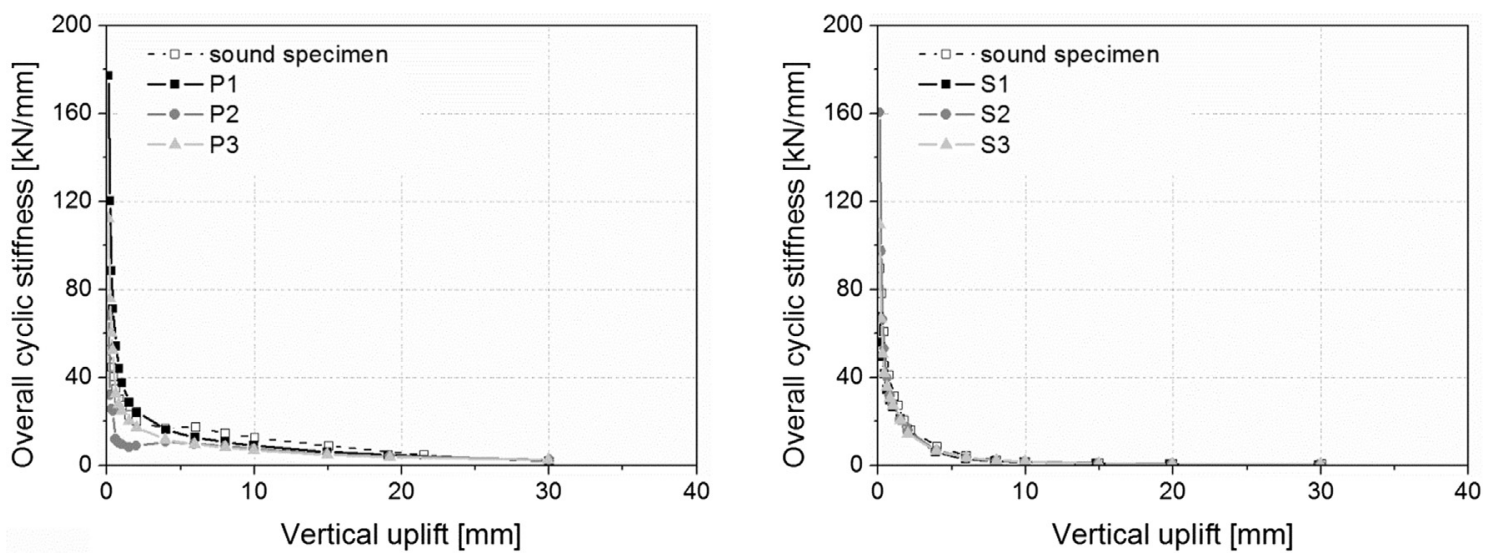

Fig. 25. Cyclic stiffness degradation: steel plates (left) and self-tapping screws (right).

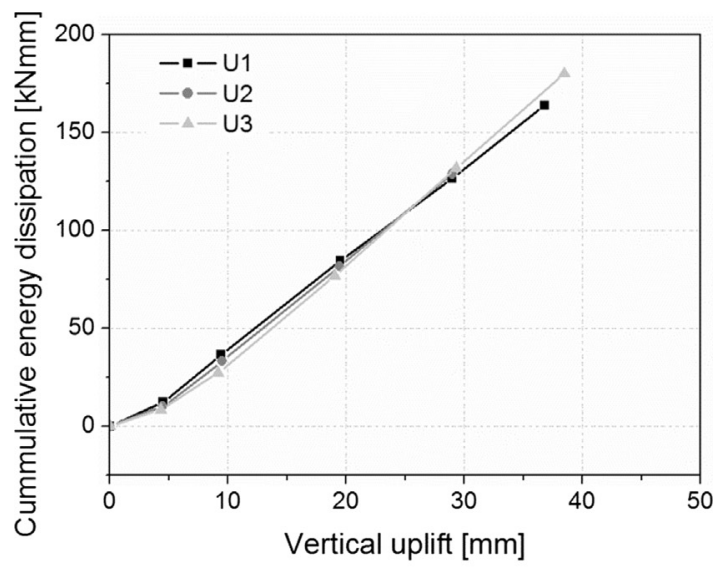

(a)

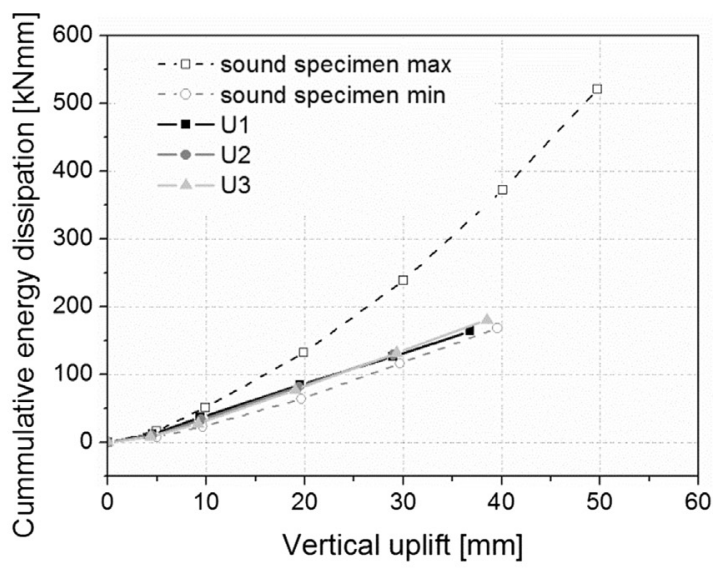

(b)

Fig. 26. Energy dissipation: unreinforced specimens: (a) comparison of weathered specimens; (b) comparison with sound specimens.

eral in the rehabilitation of timber-framed buildings, they are avoided.

On the contrary, for retrofitted specimens it appears that weathered specimens present higher dissipative capacity. This is attributed to the intrinsic behaviour of doweled joints. Sound specimens with dry timber presented a higher level of pinching, leading to a lower dissipative capacity. Steel plates were able to dissipate more than double the energy dissipated by self-tapping screws, namely $312 \%$ more (Fig. 27 ).

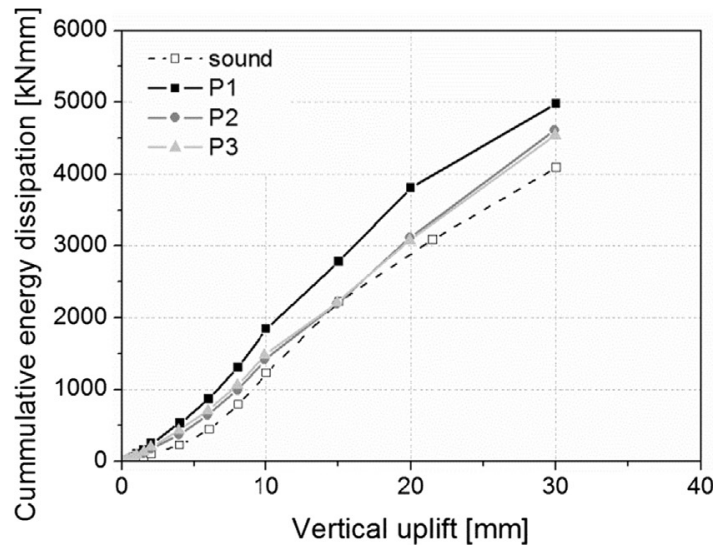

According to standard EN 12512 (2001), repetition of cycles are necessary to capture the approximate seismic response of the joint. In these repetition cycles, it is immediately evident the great loss in terms of energy dissipation (Fig. 28), as the joint presents a lot of pinching as well as strength loss, as is evident from the hysteretic loops. In both cases, the dissipative energy for the second and third repetition are very similar, indicating that dissipation occurs immediately after the first cycle.

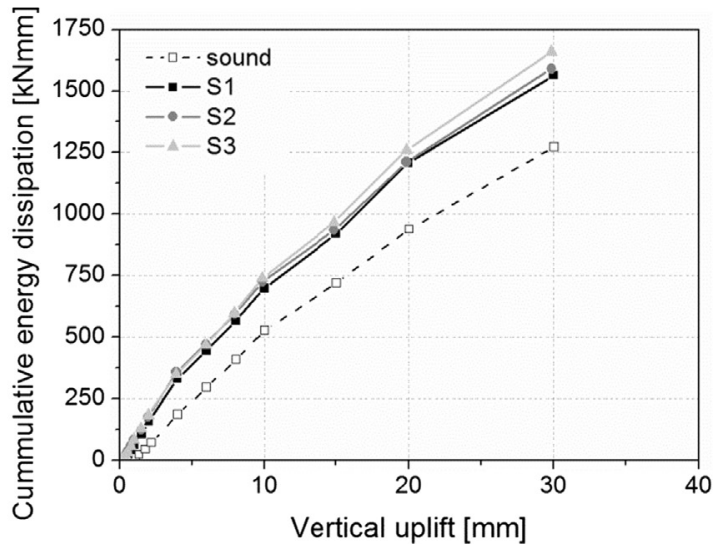

Fig. 27. Energy dissipation, strengthened specimens: steel plates (left) and self tapping screws (right). 

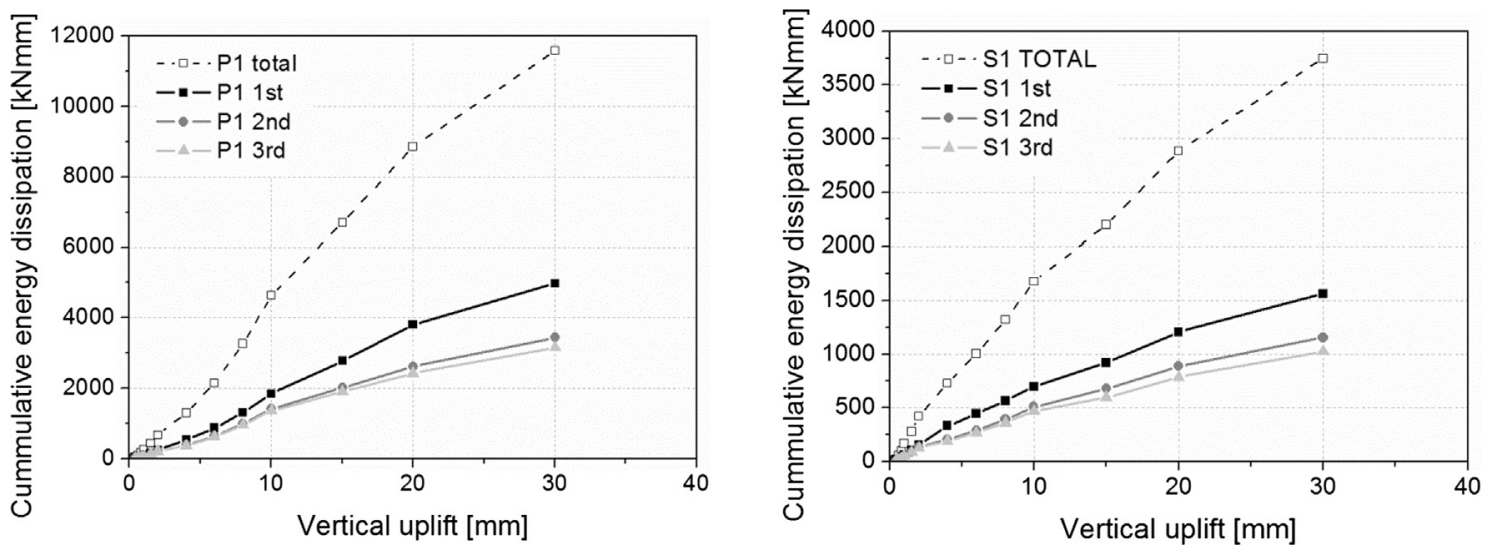

Fig. 28. Total cummulative energy: P1 specimen - steel plates (left) and self tapping screws (right).

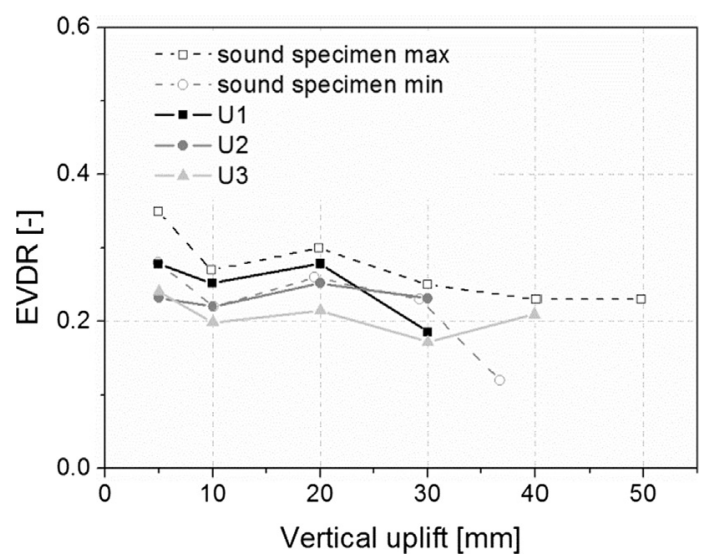

Fig. 29. Equivalent viscous damping ratio: unreinforced specimens.

4.2.2.3. Viscous damping. The equivalent viscous damping ratio (EVDR) is calculated according to the formula (Eq. (1)) proposed by Magenes and Calvi [36]:

$\zeta_{\text {eq }}=\frac{\boldsymbol{E}_{\boldsymbol{d}}}{2 \pi\left(\boldsymbol{E}_{\boldsymbol{e}}^{+}+\boldsymbol{E}_{\boldsymbol{e}}^{-}\right)}$

where $\boldsymbol{E}_{\boldsymbol{d}}$ is the dissipated hysteretic energy and $\boldsymbol{E}_{\boldsymbol{e}}^{+}$and $\boldsymbol{E}_{\boldsymbol{e}}^{-}$are the elastic energies of an equivalent viscous system calculated at maximum displacement for each direction of loading.

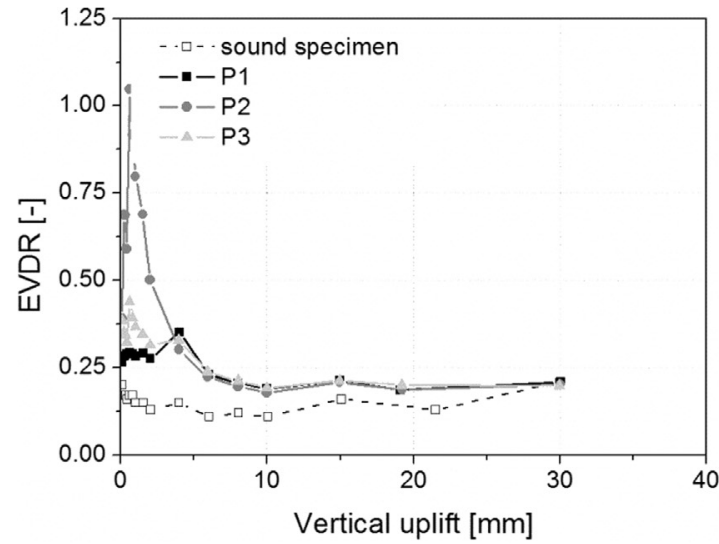

(a)
For unreinforced specimens, EVDR was within or lower than the range of sound specimens (Fig. 29), once again confirming the loss of capacity of the joint due to weathering. For strengthened connections, pinching again controls the level of damping, therefore leading to lower values of damping for sound specimens which presented higher levels of pinching. In case of steel plates (Fig. 30a), all weathered specimens present higher values of EVDR, particularly for low levels of uplift, stabilising in a final value practically equal to the sound specimens. In case of self-trapping screws (Fig. 30b), the values of EVDR are always higher, which is attributed to a more dissipative response.

\section{Conclusions}

Little to no information is available in literature on the mechanical response of traditional timber structures after being exposed to extreme climatic events. However, due to the changing climate in the last decades, with changing rain patterns and temperatures, it is considered to be important to evaluate the capacity of traditional structures to events for which they are not prepared.

This is particularly true when taking into consideration vernacular architecture, which does not follow specific design rules and it is usually passed from generation to generation as know-how. In order to protect such structures, which constitute an important heritage of a number of countries, a better understanding of the durability of the materials and their structural components is necessary.

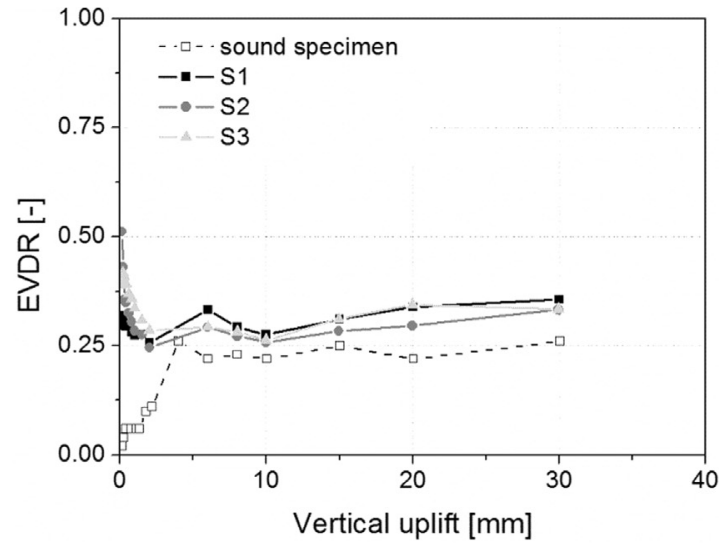

(b)

Fig. 30. Equivalent viscous damping ratio: (a) steel plates; (b) self-tapping screws. 
In this paper, traditional carpentry joints used in timber-framed infill walls were analysed and subjected to wetting/drying cycles for different periods of time. Both unreinforced and retrofitted joints were considered in the study. After weathering, the joints were dried using fans and heaters in order to recover as much as possible their original humidity. The joints were then tested mechanically and the results were compared to those of sound specimens previously tested.

For unreinforced specimens, it is clear that a sound specimen with no gaps subjected to a period of weathering will compromise its capacity in terms of strength, stiffness and energy dissipation. This is due to the appearance of gaps in the joint during the drying period that were not present before, thus greatly weakening the joint for the mechanical test taken into consideration here (pullout test). A decrease of $30 \%$ in the capacity of the joints was recorded.

For strengthened joints (in the present study steel plates and self-tapping screws were used), the trend is not so clear. The failure mechanisms changed, particularly for the steel plates strengthening, and less pinching was present. In particular, though the joints lost some strength capacity, but they showed a post-peak response similar to that of sound specimens. The joints did not lose their dissipative capacity due to a lesser degree of pinching and a more deformable material (timber), which inside the notched joint had not reached the initial $\mathrm{RH}$ of $12 \%$. The steel plates had the tendency to trap inside the moisture, therefore slowing down the drying process. The capacity of strengthened joints decreased by $31 \%$ for steel plates and by $11 \%$ for self-tapping screws.

The is an initial study which already provides trustworthy results, but of course further investigations are necessary in order to understand the relationship between the exposure of traditional/historic structures to extreme weather conditions, and the subsequent effects on the integrity, strength and durability of the structures.

This study provides information on the level of degradation of weathered joints and the influence of different types of strengthening. It is evident that the desired effect of strengthening was reduced in terms of efficiency due to wetting/drying cycles and the impossibility to reach the original $\mathrm{RH}$ of the joint. This should be taken into consideration in design, when there is the possibility of water damage. The torsional effect observed during the drying process should also be taken into consideration at a larger scale, since this could affect the in-plane response of a timber-framed wall.

The weathering of the joints should be carried out for longer periods of time in order to see also the effect on the degradation of the dowel itself, as in this case no rust was encountered and the plates, bolts and screws were in excellent conditions.

Further developments of this study include the application of different strengthening techniques and the use of water with pollutants. Moreover, infill should also be explicitly included to better understand the adsorption of water through the cross-section. Different cross-sectional dimension should also be considered in order to take into account the size effect.

An investigation on possible mitigation strategies against the deterioration of timbers structural elements is also essential for the preservation of historic structures.

\section{Conflict of interest}

\section{None.}

\section{Acknowledgments}

The research has been supported by the Portuguese Foundation of Science and Technology through grant SFRH/BPD/99891/2014 and the SAHC Consortium.

\section{References}

[1] R. Langenbach, From "Opus Craticium" to the "Chicago Frame": earthquakeresistant traditional construction, Int. J. Arch. Her. 1 (1) (2007) 29-59.

[2] G. Vasconcelos, E. Poletti, Traditional timber frame walls: mechanical behavior analysis and retrofitting, in: Panagiotis G. Asteris, Vagelis Plevris (Eds.), Part of Handbook of Research on Seismic Assessment and Rehabilitation of Historic Structures, IGI Global, 2009, pp. 30-59.

[3] V. Stephenson, D. D'Ayala, A new approach to flood vulnerability assessment for historic buildings in England, Nat. Hazards Earth Syst. Sci. 14 (2014) 10351048 .

[4] A.C. Bradley, W.S. Chang, R. Harris, The effect of simulated flooding on the structural performance of light frame timber shear walls - an experimental approach, Eng. Struct. 106 (2016) 288-298.

[5] A.C. Bradley, W.S. Chang, R. Harris, The effect of drying condition on post flooding mechanical properties of timber shear walls, Proc. World Conference on Timber Engineering, 2014.

[6] T. Pazlar, M. Kramar, Traditional timber structures in extreme weather conditions, Int. J. Arch. Her. (2015), https://doi.org/10.1080/ 15583058.2015 .1041195$.

[7] K.P.C. Rao, L.V. Verchot, J. Laarman, Adaptation to climate change through sustainable management and development of agroforestry systems, J. SAT Agric. Res. 4 (1) (2008) 1-30.

[8] C. Sabbioni, B. Brimblecombe, M. Cassar, The atlas of climate change impact on European cultural, Heritage: Scientific Analysis and Management Strategies, Anthem Press, 2010.

[9] D. Gülhan, I.O. Güney, The behaviour of traditional building systems against earthquake and its comparison to reinforced concrete frame systems: experiences of Marmara earthquake damage assessment studies in Kocaeli and Sakarya, Proceedings of Earthquake-safe: Lessons to be Learned from Traditional Construction, 2000.

[10] R. Langenbach, DON'T TEAR IT DOWN! Preserving the Earthquake Resistant Vernacular Architecture of Kashmir, UNESCO, New Delhi, 2009.

[11] A. Doğangün, O.I. Tuluk, R. Livaoğlu, R. Acar, Traditional wooden buildings and their damages during earthquakes in Turkey, Eng. Fail. Anal. 13 (2006) 981996.

[12] P. Gulkan, R. Langenbach, The earthquake resistance of traditional timber and masonry dwellings in Turkey, 13th World Conference on Earthquake Engineering, 2004.

[13] S. Santos, Tests of Pombalino walls (in Portuguese) Nota Técnica N 15/97-NCE, LNEC, Lisbon, 1997.

[14] H.A. Meireles, Seismic Vulnerability of Pombalino Buildings PhD Thesis, IST Instituto Superior Técnico, Lisbon, Portugal, 2012.

[15] E. Poletti, G. Vasconcelos, Seismic behaviour of traditional timber frame walls: experimental results on unreinforced walls, Bul. Earthq. Eng. 13 (3) (2015) 885-916.

[16] A. Gonçalves, Structural Rehabilitation of Frontal Walls in Pombalino Buildings (in Portuguese) Dissertation, University of Lisbon, 2015.

[17] V. Cóias, Structural Rehabilitation of Ancient Buildings (in Portuguese), ARGUMENTUM, GECOPRA, Lisbon, 2007.

[18] N. Ruggieri, G. Tampone, R. Zinno, In-plane vs out-of-plane "Behaviour" of an Italian timber framed system: the Borbone constructive system. Historical analysis and experimental evaluation, Int. J. Arch. Her. 6 (2015) 696-711.

[19] N. Quinn, D. D’Ayala, T. Descamps, Structural characterisation and numerical modelling of historic Quincha walls, Int. J. Arch. Her. (2016), https://doi.org/ 10.1080/15583058.2015.1113337.

[20] F. Vieux-Champagne, Y. Sieffert, S. Grange, A. Polastri, A. Ceccoti, L. Daudeville, Experimental analysis of seismic resistance of timber-framed structures with stones and earth infill, Eng. Struct. 69 (2014) 102-115.

[21] A. Dutu, M. Niste, I. Spatarelu, D.I. Dima, S. Kishiki, Seismic evaluation of Romanian traditional buildings with timber frame and mud masonry infills by in-plane static cyclic tests, Eng. Struct. (2018), https://doi.org/10.1016/j. engstruct.2018.02.062.

[22] J. Branco, Influence of the Joints Stiffness in the Monotonic and Cyclic Behaviour of Traditional Timber Trusses. Assessment of the Efficacy of Different Strengthening Techniques PhD Thesis, University of Minho, Portugal, 2008.

[23] M.A. Parisi, M. Piazza, Seismic behavior and retrofitting of joints in traditional timber roof structures, Soil Dyn. Earthq. Eng. 22 (2002) 1183-1191.

[24] T. Tannert, F. Lam, T. Vallée, Strength prediction for rounded dovetail connections considering size effects, J. Eng. Mech. 136 (3) (2010) 358-366.

[25] J.D. Shanks, P. Walker, Experimental performance of mortice and tenon connections in green oak, Struct. Eng. 6 (2005) 40-45.

[26] J.M. Branco, T. Descamps, Analysis and strengthening of carpentry joints, Constr. Build. Mat. 97 (2015) 34-47.

[27] H. Koch, L. Eisenbut, W. Seim, Multi-mode failure of form-fitting timber connections - experimental and numerical studies on the tapered tenon joint, Eng. Struct. 48 (2013) 727-738.

[28] B.H. Xu, M. Taazount, A. Bouchaïr, P. Racher, Numerical 3D finite element modelling and experimental tests for dowel-type timber joints, Constr. Build. Mat. 23 (2009) 3043-3052.

[29] W.M. Bulleit, L.B. Sandberg, M.W. Drewek, T.L. O’Bryant, Behavior and modeling of wood pegged timber frames. J. Struct. Eng 125 (1) (1999) 3-9.

[30] W.-S. Chang, M.-F. Hsu, K. Komatsu, Rotational performance of traditional Nuki joints with gap I: theory and verification, J. Wood Sci. 52 (2006) 58-62. 
[31] D.F. D'Ayala, P.H. Tsai, Seismic vulnerability of historic Dieh-Dou timber structures in Taiwan, Eng. Struct. 30 (2008) 2101-2113.

[32] F. Vieux-Champagne, S. Grange, Y. Sieffert, L. Daudeville, A. Ceccotti, A. Polastri, Experimental analysis of seismic resistance of shear wall in traditional Haitian houses, Proceedings of the 15th World Conference on Earthquake Engineering (15WCEE), 2012.

[33] M. Premrov, P. Dobrila, B.S. Bedenik, Analysis of timber-framed walls coated with CFRP strips strengthened fibre-plaster boards, Int. J. Solids Struct. 41 (2004) 7035-7048.
[34] E. Poletti, G. Vasconcelos, J.M. Branco, A.M. Koukouviki, Performance evaluation of traditional timber joints under cyclic loading and their influence on the seismic response of timber frame structures, Const. Build. Mat. 127 (2016) 321-334.

[35] B. Isopescu, Analysis of the behaviour of traditional carpentry joints - effects of extreme climatic conditions, MSc Thesis, Portugal. 2016.

[36] G. Magenes, G.M. Calvi, In-plane seismic response of brick masonry walls, Earthq. Eng. Structl. Dyn. 26 (1997) 1091-1112. 